\title{
Inventory and Ordering Decisions in Dual-Channel Supply Chains Involving Free Riding and Consumer Switching Behavior with Supply Chain Financing
}

\author{
Senyu Xu, Huajun Tang $\mathbb{D}^{\mathbb{D}}$, and Zhijun Lin \\ School of Business, Macau University of Science and Technology, Macau, China \\ Correspondence should be addressed to Huajun Tang; hjtang@must.edu.mo
}

Received 15 February 2021; Revised 8 March 2021; Accepted 23 March 2021; Published 12 April 2021

Academic Editor: Baogui Xin

Copyright (c) 2021 Senyu Xu et al. This is an open access article distributed under the Creative Commons Attribution License, which permits unrestricted use, distribution, and reproduction in any medium, provided the original work is properly cited.

\begin{abstract}
This study introduces a dual-channel supply chain including a supplier and a retailer with capital constraints, in which the retailer can apply for the trade credit financing from the supplier. This work investigates the effects of two typical behaviors, free riding behavior and consumer switching behavior, on inventory, ordering, and sales effort decisions in decentralized and centralized decision situations with stochastic demand. In order to achieve the optimal performance in the centralized system, this research designs a partial buyback contract to coordinate the supply chain. Furthermore, numerical analysis is provided to test the feasibility of the model. The results indicate that in the dual-channel supply chain with the above two behaviors, (1) the optimal sales effort level, optimal order quantity, the optimal offline, and online profits under the centralized decision-making are more than those under decentralized scenario, except for the optimal inventory level; (2) the increase of the offline consumer switching rate will lead to the reduction of the offline order quantity and the offline expected profit and raise the online inventory level and the online expected profit; (3) the increase of the online consumer switching rate will raise the offline order quantity and the offline expected profit but has no significant impact on the online inventory level and the online expected profit; (4) the increase of the free riding coefficient of the supplier, no matter whether in decentralized or centralized systems, will reduce the offline sales effort level, the offline expected profit, and the online expected profit and raise the inventory level. Finally, this work provides some managerial implication.
\end{abstract}

\section{Introduction}

As important contributors in economy, small- and mediumsized enterprises (SMEs) often confront with the problem of capital constraints, particularly in the stage of purchasing. Generally, commercial banks can provide financing solutions for SMEs. However, due to the small business scale, weak business capacity, low credibility, less assets, insufficient collateral, weak comprehensive strength, and other reasons, SMEs often cannot obtain the credit, and it is difficult for them to apply for financing [1]. Thus, capital constraints and financing difficulties have become the main problems hindering the development of SMEs [2]. Hence, trade credit financing is widely used in real transactions, which is usually provided by the core firms in the upstream of the supply chain [3]. For example, IBM provides short- term and long-term loans to customers through its whollyowned subsidiary IBM Global Financing to help them to buy IBM software. Ford, through its wholly-owned subsidiary credit company, provided wholesale loans to dealers to purchase vehicles [4].

Furthermore, with the popularity of the new retail business and the development of e-commerce in the retailing industry, a growing body of companies, such as Apple, Nike, and Samsung, not only use traditional offline channels but sell products directly to customers by opening online channels as well $[5,6]$. The existing dual-channel supply chain models can be divided into three types. The first is led by strong manufactures mastering core technology, such as Huawei and Apple in the mobile phone industry, and Intel and Qualcomm in the equipment manufacturing industry; the second is controlled by strong retailers, such as 
traditional large retailers represented by Suning and Gome, and large online retailers represented by Tmall and Jingdong; the third is vertical equilibrium; that is, manufactures and retailers have equal power, such as Starbucks and UNIQLO, which cooperate with Sephora (the global cosmetics retail authority) [7]. Online channels can help manufacturers reduce costs, better forecast customer's demand, and increase revenue [8]. In the dual-channel supply chain, consumer behavior will have two main impacts on the decision-making of supply chain members: consumer switching behavior and free riding across channels $[9,10]$. Since the same product will be sold in online channel and offline channel, there exists the mutual substitution between two channels. And consumers will turn to the other channel to purchase products when the one channel is out of stock [11]. At the same time, with the introduction of online channels, manufacturers with no sales efforts will indirectly share one part of the increase of sales brought about by retailers' sales efforts [12]. Therefore, free riding will hinder retailers' sales efforts and affect their promotion strategies [13].

Finally, it is well-known that "the best performance" of supply chain members will be difficult to achieve without coordination, which means that the total performance cannot be best possible although the decisions of both sides are optimal [14]. Thus, the contract coordination is vital to coordinate and improve the profits of each partner in dual-channel supply chains, so as to alleviate the competition between channels and the pressure of financing to a certain extent. Based on our best knowledge, the existing study has less investigated the impacts of free riding and consumer switching behavior on the dualchannel supply chain performance with capital constraints.

Hence, this study aims to take free riding and consumer switching behavior into account, investigates their impacts on dual-channel supply chain performance, proposes the financing solution for the retailer with the capital constraint, and designs the contract coordination to help supply chain members achieve the global optimum.

This research contributes to the study of supply chain financing in the field of capital-constrained dual-channel supply chains with stochastic demand, conducts a deep investigation of two main impacts of consumer switching behavior and free riding on supply chain performance, and provides some scientific and reasonable support for decision makers.

The rest of this study is organized as follows. Sections 2 and 3 present the literature review and the problem and model description, respectively. Section 4, based on trade credit financing, free riding, and consumer switching behavior, analyzes the optimal solutions of inventory level, order quantity, and sales effort level in the decentralized and centralized supply chains. Section 5 proposes a partial buyback to coordinate the supply chain. Section 6 tests the feasibility of the model with a numerical example and provides the sensitivity analysis of the parameters. Finally, Section 7 concludes this study and puts forward some managerial implications.

\section{Literature Review}

In this section, the literature studies on supply chain financing, dual-channel supply chain, free riding, and supply chain coordination will be reviewed, respectively.
2.1. Supply Chain Financing. Supply chain financing (SCF) refers to promoting interorganizational capital flow through financing schemes provided by financial institutions, improving the supply chain management of cash flow, and ensuring the smooth implementation of transaction between supply chain members. [15]. SCF provides optimal financing conditions and sufficient funds, which can raise the supply chain members' performance, so as to ensure the long-term and effective operations of the supply chain [16]. Among them, bank loan and trade credit have been concerned by many scholars. A large number of literature studies have studied the problem that enterprises can ease the capital constraints through bank loans [17-21]. Among them, Dada and $\mathrm{Hu}$ [18] studied a newsboy model in which retailers with capital constraints can apply for financing through banks. Feng et al. [20] researched the optimal ordering strategy of the buyer under the bank financing and found that the buyer's order quantity and profit would raise with the increase of bank loan quota. Yan et al. [21] considered that the manufacturer provided credit guarantee for the retailer, investigated the influence of bank loan on retailer financing equilibrium and coordination. Trade credit is a kind of credit provided by the upstream enterprises to the downstream firms. By charging the loan interest, the downstream firms can purchase the product from the upstream enterprises in the case of delayed payment and pay back with the sales profit in the end of the sales cycle. Some scholars pointed out that retailers prefer trade credit than bank loans because of lower interest rates. For instance, Kouvelis and Zhao [22] found that, if providing an optimal structure of trade credit, retailers always preferred trade credit rather than bank financing, because risk neutral suppliers would always provide financing solutions for retailers with interest rate at most risk-free interest rate. Hua et al. [4] investigated a capital-constrained retailer ordering decision from suppliers through option contract by establishing a Stackelberg game model, and the retailer could apply for bank loans or trade credit financing from suppliers if needed. They also analyzed the financing problems in the supply chain and found that the retailer always tended to obtain financing from the supplier because of the low interest rate. Some scholars also claimed that, compared with bank loans, trade credit can reduce the double marginalization by risk sharing [23-25]. Among them, Jing and Seidmann [23] showed that trade credit, compared with bank loans, was more effective to alleviate double marginalization when the production cost was relatively low, because manufacturers and retailers shared the risk of low demand. Yang and Birge [25] suggested that trade credit enabled to raise the efficiency of the supply chain by sharing demand risk between retailers and suppliers. It can be found that most of the existing studies on SCF focused more on single-channel supply chains and less on dual-channel supply chains which consist of retailer's offline channel and supplier's online channel.

2.2. Dual-Channel Supply Chain. As the rapid development of e-commerce, the dual-channel supply chain has become one popular research topic in the last decade. It makes easier 
for many manufacturers to carry on online direct sales [5]. Most of researchers have studied the effect of pricing decisions on dual-channel supply chain. For instance, Chen et al. [26] considered manufacturer as the leader of Stackelberg game and retailer as the follower, studied the pricing decision and coordination by developing dual-channel supply chain model. Ma et al. [27] researched the pricing decision of dual-channel closed-loop supply chain by considering the government consumption subsidies and consumer channel preferences. Ding et al. [28] investigated the decision-making process of hierarchical pricing in different channel models and obtained the joint optimization strategy of offline retailer's sales price, online manufacturer's sales price, and wholesale price. Dai et al. [29] investigated the impact of retailers' fair concerning on the pricing decisions of the manufacture and the retailer by establishing the dualchannel supply chain model. Wang et al. [30] considered the sales effort and third-party product recovery, researched the optimal pricing of retail channel and direct channel of the dual-channel supply chain. Xu et al. [31] investigated the pricing decision and channel strategy of dual-channel supply chain under the manufacture had condition of sufficient and insufficient funds. Qin et al. [8] discussed the impact of a trade credit policy (delayed payment) on pricing decisions and alleviating conflicts arising on a dual-channel supply chain including one value-added retailer and one manufacturer and. In addition, inventory and ordering decisions are also one of the important problems for the supply chain members' decision. In contrast, few researchers have researched the inventory and ordering decisions in dualchannel supply chain. Among them, due to the mutual substitution of the same product between the two channels, customers usually switch to one channel to purchase when the other channel is out of stock, which leads to some studies on the problem of consumer switching behavior. For example, Chiang and Monahan [32] assumed that the demand was stochastic and developed a two-stage dual-channel inventory model, studied the inventory level decisions and control strategy where there was a shortage substitution between two different channels. Boyaci [33] established a newsboy model to analyze the optimal inventory decisions and revenues by considering the impact of consumer switching behavior. Geng and Mallik [34] considered the supplier's capacity shortage and investigated how the capacity constraint affected the manufacturer's optimal inventory allocation strategy, the retailer's order decision, and the equilibrium of the game under the consumer switching behavior and inventory competition. Yang et al. [35] studied the influence of delivery lead time and consumer switching behavior on the inventory decisions under the decentralized and centralized scenarios, discussed the inventory competition between online and offline channels, and found that at least one member would be overstocked in the decentralized system. Most of the above studies on the dual-channel supply chain assumed that members have no capital constraint and mainly focused on pricing decision if cash flow is limited. However, in real business, retailers, as the downstream SMEs in the supply chain, often face the problem of capital constraints. Hence, this work considers the retailer has shortage of capital, and combining with SCF, the inventory and ordering decisions in dual-channel supply chains are studied.

2.3. Free Riding. For another, there usually exists the free riding behavior based on sales effort in dual-channel supply chains [13]. When the offline retailers carry out various promotion activities (such as advertising and product experience), consumers can first enjoy the product brought by the promotion effect of offline retailing stores and then buy the product at a lower price by switching to online channels. Van Baal and Dach [36] found that in dual-channel supply chains, more than $20 \%$ of consumers have free riding behavior. He et al. [37] developed a dual-channel closed-loop supply chain and investigated the impact of free riding on carbon emissions in a product's life cycle. Zhou et al. [12] considered a two-echelon supply chain that manufacturers sold products through online and offline channels, in which retailers provided some presale service to customers, and researched the influence of free riding on pricing decision, service strategies, and profits of manufacturers and retailers based on consistent and inconsistent pricing. Chen and Chen [38] investigated the impact of free riding behavior on price matching strategy of physical retailers by developing a duopoly game using the Hotelling model. Zhang et al. [39] considered the supply chain including two kinds of manufacturers (i.e., free riding and green innovation), established a differential game model, and researched the dynamics of green innovation. Yan et al. [40] considered an online financing service for suppliers with capital constraint could be provided by an e-commerce platform and studied the effects of online financing and free riding on sales effort, optimal pricing, and order quantity. Thus, this study combines the free riding behavior with consumer switching behavior in the dual-channel supply chain.

2.4. Supply Chain Coordination. It is well known that the centralized decision can lead to the global optimum of the supply chain performance, but it does not provide specific profit allocation mechanisms. Hence, coordination mechanism is introduced to help each member in the supply chain with global optimum profit achieve Pareto-optimal. There exists some classic literature focusing on quantity discount, revenue sharing, buyback, quantity flexibility, effort cost sharing, and other contracts to coordinate supply chain [41-45]. After that, many scholars coordinate the supply chain by developing different contracts for specific situations. Among them, Xie et al. [46] proposed a bilateral buyback contracted to coordinate an intermodal transport system including one liner firm at a seaport and one railway transport firm at a dry port. Zhong et al. [47] analyzed the impact of revenue sharing contract on a three-stage logistics service supply chain, which composed of terminal distributors, express delivery companies, and e-commerce malls, and found that the contract could raise all members' profit, so as to get win-win situation. Xie et al. [48] investigated the impact of relative bargaining power and income uncertainty on the performance of buyback contract by developing a 
two-echelon supply chain including one seller and one buyer and considered that the buyer had uncertain demand and income. Zhong et al. [49] researched the coordination effect of unit delivery price, cost sharing, and revenue sharing contracts in the three semicentralized alliances by developing a three-stage supply chain composed of express company, e-commerce mall, and terminal distribution service provider based on Stackelberg game theory. Table 1 lists some key-related literature so as to illustrate the innovation and contribution of this work.

In summary, most of the existing studies mainly focused on single-channel supply chains, or dual-channel supply chains with sufficient funds, and less investigated the cases with capital constraints. Furthermore, in the dual-channel supply chains, most of research studies focus more on members' pricing decisions and less on inventory and ordering decisions. And there is little research taking into account the two main behaviors: consumer switching behavior and free riding behavior, and we discussed their influence on the optimal inventory level and ordering decisions.

Hence, this study considers consumer switching behavior and free riding behavior in a dual-channel supply chain, where the supplier sells directly through its own online channel and offline retailer channel. Furthermore, it investigates their impacts on the sales effort level of the retailer, ordering quantity and the supplier' inventory decisions with constrained capitals under the stochastic demand.

\section{Problem and Model Description}

3.1. Problem Description. This work considers a dualchannel supply chain system including a risk neutral retailer and a risk neutral supplier. The retailer and the supplier sell the same type of product through their own offline and online channel. At the beginning of the sales cycle, the retailer, as an SME in the downstream of the supply chain, has capital constraint. Its initial capital is enough to cover the cost of sales effort, but not sufficient to cover all purchasing cost. In this case, the supplier, as the core enterprise of supply chain, has enough capital and can provide trade credit financing solutions for the retailer through its own financial subsidiary corporation. Thus, the retailer can use financing capital to continuously purchase products from the supplier, which is not allowed to be used for another project investment [4]. At the end of the sales period, the retailer and the supplier deal with the unsold products at the residual price, respectively, and the retailer needs to repay the loan and financing interest to the supplier. Meanwhile, the problem considers the possibility of the retailer bankruptcy; that is, the retailer's sales profit may insufficient to pay all the loan and financing interest (Figure 1).

Furthermore, this study considers the influence of "free riding" behavior and consumer switching behavior on the supply chain decision and aims to maximize total supply chain performance. The feasibility of the model will be tested in the numerical analysis in Section 6.
Finally, the problem assumes that the order quantity and inventory level decisions are short-term strategies, and the sales effort level is a long-term strategy. Therefore, the sales effort decision should be determined before the inventory level and order quantity decisions. Under the decentralized decision, the retailer sets the sales effort level at first. Then, the supplier and the retailer make inventory level and order quantity decisions simultaneously (the Stackelberg game sequence). Under the centralized dual-channel supply chain, referring to Hua et al [6] and Yang et al. [35], this work uses the two-stage optimization to maximize the expected profit. First, the whole supply chain sets the sales effort level. Then, it makes inventory level decision and order quantity decision simultaneously.

3.2. Notation Definition. To formulate feasible models, some related notation is defined in Table 2.

3.3. Model Description. At the beginning of the sales cycle, the retailer has initial capital $B$, and the supplier provides credit loans with interest rate of $I$ and wholesale price $w$ for the retailer. The retailer sets sales effort level $e$ at first. Then, the retailer determines the order quantity $Q_{r}$ and the supplier decides the inventory level $Q_{s}$ for the online channel simultaneously. And the retailer will apply for the financing amount $L=w Q_{r}+R(e)-B$ where $R(e)=\eta e^{2} / 2$ is the cost of sales effort and $\eta$ is the cost factor of sales effort $[12,50]$. Then, the supplier produces products for its own online channel and offline channel at unit cost $c_{o}$ and sells them in its own online channel with the price $p_{s}$. At the same time, the retailer buys the product from the supplier with the wholesale price $w$ and sells the product to the customer via its offline channel at the retail price $p_{r}$. At the end of the sales period, the supplier and the retailer process the unsold products, respectively, at the price $v$, and the retailer has to pay back the loan and financing interest owed by the supplier. This study assumes that all prices are exogenous [35], and the risk-free interest rate is 0 . To ensure the smooth progress of the transaction, this work also assumes that $v<c_{o}<w<w(1+I)<p_{r}, p_{s}$. Furthermore, the model sets a critical value of demand $z$, which implies that the critical point at the retailer's sales profit is enough to cover the supplier's loan and interest, i.e.,

$$
z=\frac{\left(w Q_{r}+R(e)-B\right)(1+I)-v Q_{r}}{p_{r}-v} .
$$

It means that, the retailer can only use its sales revenue to pay back when the sales revenue is not enough to repay all the outstanding loans and financing interest; otherwise, it needs to pay back the amount of $L(1+I)$ with interest and principal.

Note that $z=0$ if the retailer's initial capital is sufficient. For another, the trade credits are not used for the retailer if $z>Q_{r}$. Then, the retailer applies for trade credit if $0<z<Q_{r}$. Hence, this study assumes that $0<z<Q_{r}$ [51]. 
TABLE 1: List of key-related literature.

\begin{tabular}{|c|c|c|c|c|c|c|}
\hline $\begin{array}{l}\text { Key-related } \\
\text { studies }\end{array}$ & Decision variables & Financing type & $\begin{array}{l}\text { Channel } \\
\text { type }\end{array}$ & Contract strategy & $\begin{array}{l}\text { Consumer } \\
\text { switching }\end{array}$ & $\begin{array}{l}\text { Free } \\
\text { riding }\end{array}$ \\
\hline $\begin{array}{l}\text { Hua et al. } \\
(2019)\end{array}$ & $\begin{array}{l}\text { Supplier's interest rate; retailer's } \\
\text { ordering; supplier's option } \\
\text { price }\end{array}$ & Trade credit & $\begin{array}{l}\text { Offline } \\
\text { channel }\end{array}$ & Option contract & No & No \\
\hline $\begin{array}{l}\text { Kouvelis and } \\
\text { Zhao (2012) }\end{array}$ & $\begin{array}{l}\text { Retailer's ordering; credit } \\
\text { guarantee coefficient }\end{array}$ & $\begin{array}{l}\text { Bank financing; trade } \\
\text { credit }\end{array}$ & $\begin{array}{l}\text { Offline } \\
\text { channel }\end{array}$ & $\begin{array}{l}\text { Manufacturer's trade } \\
\text { credit guarantee }\end{array}$ & No & No \\
\hline $\begin{array}{l}\text { Yang and Birge } \\
(2018)\end{array}$ & $\begin{array}{l}\text { Retailer's ordering; supplier's } \\
\text { whole sale price }\end{array}$ & $\begin{array}{l}\text { Bank financing; trade } \\
\text { credit }\end{array}$ & $\begin{array}{l}\text { Offline } \\
\text { channel }\end{array}$ & $\begin{array}{l}\text { Early-payment } \\
\text { discount }\end{array}$ & No & No \\
\hline Dai et al.(2019) & $\begin{array}{l}\text { Online selling price; wholesale } \\
\text { price; offline selling price }\end{array}$ & 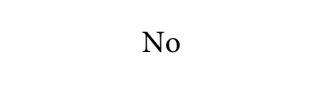 & $\begin{array}{l}\text { Dual- } \\
\text { channel }\end{array}$ & $\begin{array}{l}\text { Retailers' fairness } \\
\text { concerns }\end{array}$ & No & No \\
\hline $\begin{array}{l}\text { Wang } \\
\text { et al.(2020) }\end{array}$ & $\begin{array}{l}\text { Online selling price; wholesale } \\
\text { price; offline selling price; } \\
\text { collection price }\end{array}$ & No & $\begin{array}{l}\text { Dual- } \\
\text { channel }\end{array}$ & (5 & No & No \\
\hline $\begin{array}{l}\text { Geng and } \\
\text { Mallik (2007) }\end{array}$ & $\begin{array}{c}\text { Retailer's ordering; } \\
\text { manufacture's inventory }\end{array}$ & No & $\begin{array}{l}\text { Dual- } \\
\text { channel }\end{array}$ & $\begin{array}{c}\text { Reverse revenue } \\
\text { sharing }\end{array}$ & Yes & No \\
\hline $\begin{array}{l}\text { Yang et al. } \\
(2017)\end{array}$ & $\begin{array}{l}\text { Delivery lead time; retailer's } \\
\text { ordering; manufacture's } \\
\text { inventory }\end{array}$ & No & $\begin{array}{l}\text { Dual- } \\
\text { channel }\end{array}$ & No & Yes & No \\
\hline $\begin{array}{l}\text { Zhou et al. } \\
\text { (2018) }\end{array}$ & $\begin{array}{l}\text { Retailer's sales price; } \\
\text { manufacture's sales price; } \\
\text { retailer's service level }\end{array}$ & No & $\begin{array}{l}\text { Dual- } \\
\text { channel }\end{array}$ & Service-cost sharing & No & No \\
\hline $\begin{array}{l}\text { Qin et al. } \\
(2020)\end{array}$ & $\begin{array}{l}\text { Retailer's sales price; } \\
\text { manufacture's sales price }\end{array}$ & $\begin{array}{l}\text { Trade credit (delay } \\
\text { payment) }\end{array}$ & $\begin{array}{l}\text { Dual- } \\
\text { channel }\end{array}$ & Trade credit contract & No & No \\
\hline $\begin{array}{l}\text { Chen and Chen } \\
\text { (2019) }\end{array}$ & $\begin{array}{l}\text { Brick-and-mortar retailer's } \\
\text { sales price; online retailer's sales } \\
\text { price }\end{array}$ & No & $\begin{array}{l}\text { Dual- } \\
\text { channel }\end{array}$ & No & No & No \\
\hline $\begin{array}{l}\text { Yan et al. } \\
(2020)\end{array}$ & Offline price; online price & $\begin{array}{l}\text { E-commerce platform } \\
\text { finance }\end{array}$ & $\begin{array}{l}\text { Dual- } \\
\text { channel }\end{array}$ & No & No & No \\
\hline This study & $\begin{array}{c}\text { Retailer's ordering quantity and } \\
\text { sales effort level; supplier's } \\
\text { inventory level }\end{array}$ & $\begin{array}{c}\text { Trade credit (supplier's } \\
\text { financial subsidiary } \\
\text { corporation) }\end{array}$ & $\begin{array}{l}\text { Dual- } \\
\text { channel }\end{array}$ & $\begin{array}{l}\text { Partial buyback } \\
\text { contract }\end{array}$ & Yes & Yes \\
\hline
\end{tabular}

To discuss consumer switching behavior and free riding behavior simultaneously, this research refers to the models of $[11,33]$ and establishes demand functions as follows:

Demand for the retailer: $D_{r}=d_{r}+(\alpha-\beta) e+$ $K_{s}\left(d_{s}+\beta e-Q_{s}\right)^{+}$

Demand for the supplier: $D_{s}=d_{s}+\beta e+K_{r}\left(d_{r}+(\alpha-\right.$ $\left.\beta) e-Q_{r}\right)^{+}$where $d_{s}$ and $d_{r}$ are initial demands for the supplier's online channel and the retailer's offline channel, respectively, and they are both independent continuous random variables. The cumulative function and density function of $d_{s}$ and $d_{r}$ are $G(y)$ and $F(x)$, and $g(y)$ and $f(x)$, respectively. $\alpha$ is the elasticity coefficient of market demand under the given sales effort level; $\beta(0<\beta<\alpha)$ is the degree of "free riding" behavior, which is used to measure the proportion of customers who enjoy free offline channel promotion service but transfer to online channels to purchase products. $K_{r}, K_{s}$ are the switching rate of offline channel and online channel $\left(0 \leq K_{r}, K_{s}<1\right)$, respectively. That is, when the offline retail channel is out of stock, the consumer transfers to the online channel with probability $K_{r}$; when the online channel is out of stock, the consumer transfers to the offline channel with the probability $K_{s}$ (Figure 2). It should be more favorable for the retailer and the supplier to satisfy the demand in their owned channel. Hence, the model assumes that $\left(p_{r}-v\right)>K_{r}\left(p_{s}-v\right)$ and $\left(p_{s}-v\right)>K_{s}\left(p_{r}-v\right)[35]$

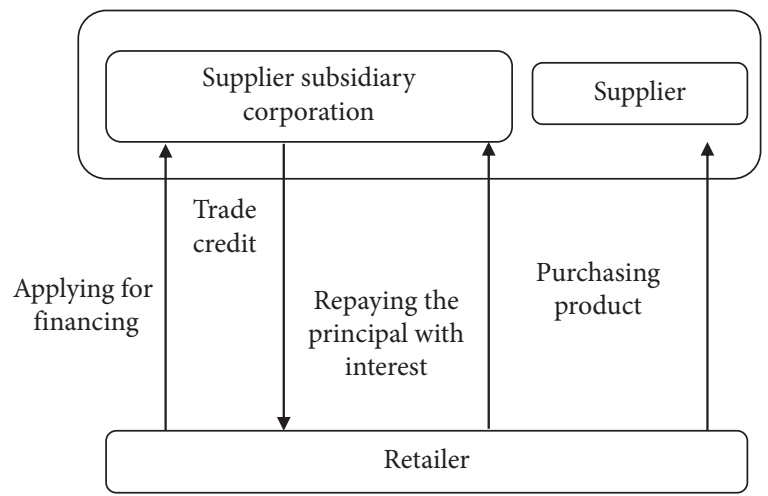

FIgURE 1: Dual-channel supply chain financing and trading process.

In the next section, the model derivation and analysis will be illustrated under the decentralized and centralized systems.

\section{Model Analysis}

4.1. Dual-Channel Supply Chain Model under the Decentralized Decision-Making. In this subsection, the supplier and the retailer make decisions so as to maximize their own profit. 
TABLE 2: Notation definition.

\begin{tabular}{lcc}
\hline $\begin{array}{l}\text { Superscripts } \\
\text { Subscripts }\end{array}$ & $n \in\{d, c, u\}$ & Decentralized $(d)$, centralized $(c)$, partial buyback contract $(u)$ \\
Retailer $(r)$, supplier $(s)$
\end{tabular}

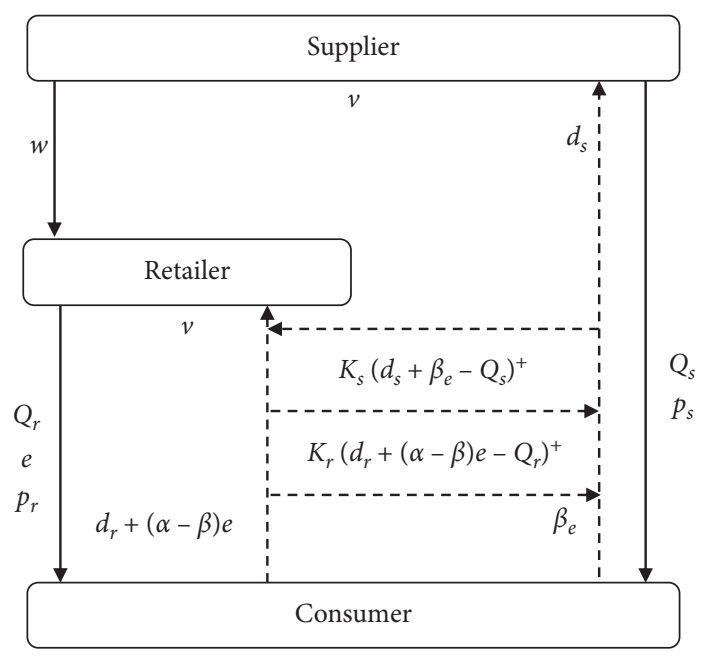

.. Demand

FIgURE 2: Dual-channel supply chain system.

The retailer's profit is defined as

$V_{r}=-B+ \begin{cases}p_{r} Q_{r}-L(1+I), & \text { if } d_{r}+(\alpha-\beta) e>Q_{r}, \\ p_{r} E \min \left(Q_{r}, D_{r}\right)+v E\left(Q_{r}-D_{r}\right)^{+}-E \min \left[L(1+I), p_{r} E \min \left(Q_{r}, D_{r}\right)+v E\left(Q_{r}-D_{r}\right)^{+}\right], & \text {if } 0<d_{r}+(\alpha-\beta) e<Q_{r}, d_{s}+\beta e>Q_{s}, \\ p_{r} D_{r}+v E\left(Q_{r}-D_{r}\right)-E \min \left[L(1+I), p_{r} D_{r}+v E\left(Q_{r}-D_{r}\right)\right], & \text { if } 0<d_{r}+(\alpha-\beta) e<Q_{r}, 0<d_{s}+\beta e<Q_{s} .\end{cases}$

And the specific terms of the retailer profit except for $-B$ are as follows:

(1) The case of $d_{r}+(\alpha-\beta) e>Q_{r}$ means that the retailer's offline demand is more than the supply of the retailer no matter whether there exists demand transfer from the supplier's online channel. It implies that the retailer's sales profit is sufficient to cover all the outstanding loans and financing interest 
$L(1+I)$. Hence, the retailer's expected profit expression can be written as

$$
V_{r 1}=\int_{Q_{r}-(\alpha-\beta) e}^{\infty}\left[p_{r} Q_{r}-\left(w Q_{r}+R(e)-B\right)(1+I)\right] f(x) \mathrm{d} x .
$$

(2) The case of $0<d_{r}+(\alpha-\beta) e<Q_{r}, d_{s}+\beta e>Q_{s}$ means that the offline demand is less than the supply of the retailer, but there exists demand transfer from the supplier's online channel. In this situation, the total offline demand of the retailer is more than the supply of the retailer if $D_{r}>Q_{r}$. When $D_{r}<Q_{r}$, the retailer's sales profit is insufficient to repay $L(1+I)$ if $D_{r}<z$, and the retailer should pay back the amount of $L(1+I)$ if $Q_{r}>D_{r}>z$. Therefore, the expected profit of the retailer under this condition is

$$
\begin{aligned}
V_{r 2}= & \int_{Q_{s}-\beta e}^{\left(Q_{r}-(\alpha-\beta) e\right) / K_{s}+Q_{s}-\beta e} \int_{z-(\alpha-\beta) e-K_{s}\left(y+\beta e-Q_{s}\right)}^{Q_{r}-(\alpha-\beta) e-K_{s}\left(y+\beta e-Q_{s}\right)} p_{r}\left(x+(\alpha-\beta) e+K_{s}\left(y+\beta e-Q_{s}\right)\right) f(x) g(y) \mathrm{d} x \mathrm{~d} y \\
& +\int_{Q_{s}-\beta e}^{\left(\left(Q_{r}-(\alpha-\beta) e\right) / K_{s}\right)+Q_{s}-\beta e} \int_{z-(\alpha-\beta) e-K_{s}\left(y+\beta e-Q_{s}\right)}^{Q_{r}-(\alpha-\beta) e-K_{s}\left(y+\beta e-Q_{s}\right)} v\left(Q_{r}-x-(\alpha-\beta) e-K_{s}\left(y+\beta e-Q_{s}\right)\right) f(x) g(y) \mathrm{d} x \mathrm{~d} y \\
& +\int_{Q_{s}-\beta e}^{\left(\left(Q_{r}-(\alpha-\beta) e\right) / K_{s}\right)+Q_{s}-\beta e} \int_{Q_{r}-(\alpha-\beta) e-K_{s}\left(y+\beta e-Q_{s}\right)}^{Q_{r}-(\alpha-\beta) e} p_{r} Q_{r} f(x) g(y) \mathrm{d} x \mathrm{~d} y \\
& -\int_{Q_{s}-\beta e}^{\left(\left(Q_{r}-(\alpha-\beta) e\right) / K_{s}\right)+Q_{s}-\beta e} \int_{z-(\alpha-\beta) e-K_{s}\left(y+\beta e-Q_{s}\right)}^{Q_{r}-(\alpha-\beta) e}\left(\left(w Q_{r}+R(e)-B\right)(1+I)\right) f(x) g(y) \mathrm{d} x \mathrm{~d} y .
\end{aligned}
$$

(3) The case of $0<d_{r}+(\alpha-\beta) e<Q_{r}, 0<d_{s}+\beta e<Q_{s}$ means that the offline demand is less than the supply of the retailer, and there is no transfer from the supplier's online channel. In this case, the total offline demand for the retailer is more than the supply of the retailer if $D_{r}>Q_{r}$. When $D_{r}<Q_{r}$, if $D_{r}<z$, the retailer's sales profit is not enough to cover $L(1+I)$, and the retailer should pay back the amount of $L(1+I)$, if $Q_{r}>D_{r}>z$. Thus, the expected profit of the retailer is

$$
\begin{aligned}
V_{r 3}= & \int_{0}^{Q_{s}-\beta e} \int_{z-(\alpha-\beta) e}^{Q_{r}-(\alpha-\beta) e} p_{r}(x+(\alpha-\beta) e) f(x) g(y) \mathrm{d} x \mathrm{~d} y \\
& +\int_{0}^{Q_{s}-\beta e} \int_{z-(\alpha-\beta) e}^{Q_{r}-(\alpha-\beta) e} v\left(Q_{r}-x-(\alpha-\beta) e\right) f(x) g(y) \mathrm{d} x \mathrm{~d} y \\
& -\int_{0}^{Q_{s}-\beta e} \int_{z-(\alpha-\beta) e}^{Q_{r}-(\alpha-\beta) e}\left(\left(w Q_{r}+R(e)-B\right)(1+I)\right) f(x) g(y) \mathrm{d} x \mathrm{~d} y .
\end{aligned}
$$

Finally, the expression of the retailer's total expected profit can be taken as follows:

$$
\begin{aligned}
\pi_{r}^{d}= & -B+V_{r 1}+V_{r 2}+V_{r 3} \\
= & p_{r} Q_{r}-\left(w Q_{r}+R(e)-B\right)(1+I)-B \\
& -p_{r} Q_{r} \int_{0}^{Q_{s}-\beta e} \int_{0}^{Q_{r}-(\alpha-\beta) e} f(x) g(y) \mathrm{d} x \mathrm{~d} y \\
& -p_{r} Q_{r} \int_{Q_{s}-\beta e}^{\left(\left(Q_{r}-(\alpha-\beta) e\right) / K_{s}\right)+Q_{s}-\beta e} \int_{0}^{Q_{r}-(\alpha-\beta) e-K_{s}\left(y+\beta e-Q_{s}\right)} f(x) g(y) \mathrm{d} x \mathrm{~d} y \\
& +\int_{Q_{s}-\beta e}^{\left(\left(Q_{r}-(\alpha-\beta) e\right) / K_{s}\right)+Q_{s}-\beta e} \int_{z-(\alpha-\beta) e-K_{s}\left(y+\beta e-Q_{s}\right)}^{Q_{r}-(\alpha-\beta) e-K_{s}\left(y+\beta e-Q_{s}\right)}\left[v Q_{r}+\left(p_{r}-v\right)\left(x+(\alpha-\beta) e+K_{s}\left(y+\beta e-Q_{s}\right)\right)\right] f(x) g(y) \mathrm{d} x \mathrm{~d} y \\
& +\int_{0}^{Q_{s}-\beta e} \int_{z-(\alpha-\beta) e}^{Q_{r}-(\alpha-\beta) e}\left[v Q_{r}+\left(p_{r}-v\right)(x+(\alpha-\beta) e)\right] f(x) g(y) \mathrm{d} x \mathrm{~d} y \\
& +\left(w Q_{r}+R(e)-B\right)(1+I) \int_{0}^{Q_{s}-\beta e} \int_{0}^{z-(\alpha-\beta) e} f(x) g(y) \mathrm{d} x \mathrm{~d} y \\
& +\left(w Q_{r}+R(e)-B\right)(1+I) \int_{Q_{s}-\beta e}^{\left(\left(Q_{r}-(\alpha-\beta) e\right) / K_{s}\right)+Q_{s}-\beta e} \int_{0}^{z-(\alpha-\beta) e-K_{s}\left(y+\beta e-Q_{s}\right)} f(x) g(y) \mathrm{d} x \mathrm{~d} y .
\end{aligned}
$$


And the retailer's expected repayment amount to the supplier is

$$
\begin{aligned}
V_{r 4}= & \left(w Q_{r}+R(e)-B\right)(1+I) \\
& +\int_{Q_{s}-\beta e}^{\left(\left(Q_{r}-(\alpha-\beta) e\right) / K_{s}\right)+Q_{s}-\beta e} \int_{0}^{z-(\alpha-\beta) e-K_{s}\left(y+\beta e-Q_{s}\right)}\left[v Q_{r}+\left(p_{r}-v\right)\left(x+(\alpha-\beta) e+K_{s}\left(y+\beta e-Q_{s}\right)\right)\right] f(x) g(y) \mathrm{d} x \mathrm{~d} y \\
& +\int_{0}^{Q_{s}-\beta e} \int_{0}^{z-(\alpha-\beta) e}\left[v Q_{r}+\left(p_{r}-v\right)(x+(\alpha-\beta) e)\right] f(x) g(y) \mathrm{d} x \mathrm{~d} y \\
& -\left(w Q_{r}+R(e)-B\right)(1+I) \int_{0}^{Q_{s}-\beta e} \int_{0}^{z-(\alpha-\beta) e} f(x) g(y) \mathrm{d} x \mathrm{~d} y \\
& -\left(w Q_{r}+R(e)-B\right)(1+I) \int_{Q_{s}-\beta e}^{\left(\left(Q_{r}-(\alpha-\beta) e\right) / K_{s}\right)+Q_{s}-\beta e} \int_{0}^{z-(\alpha-\beta) e-K_{s}\left(y+\beta e-Q_{s}\right)} f(x) g(y) \mathrm{d} x \mathrm{~d} y .
\end{aligned}
$$

Similarly, the supplier's profit is defined as

$V_{s}=-c_{o}\left(Q_{r}+Q_{s}\right)+B-R(e)+ \begin{cases}p_{s} Q_{s}+E \min \left[L(1+I), p_{r} E \min \left(Q_{r}, D_{r}\right)+v E\left(Q_{r}-D_{r}\right)^{+}\right], & \text {if } d_{s}+\beta e>Q_{s}, \\ p_{s} E \min \left(Q_{s}, D_{s}\right)+v E\left(Q_{s}-D_{s}\right)^{+}+L(1+I), & \text { if } 0<d_{s}+\beta e<Q_{s}, d_{r}+(\alpha-\beta) e>Q_{r}, \\ p_{s} D_{s}+v E\left(Q_{s}-D_{s}\right)+E \min \left[L(1+I), p_{r} D_{r}+v E\left(Q_{r}-D_{r}\right)\right], & \text { if } 0<d_{s}+\beta e<Q_{s}, 0<d_{r}+(\alpha-\beta) e<Q_{r} .\end{cases}$

And the specific terms of the supplier profit function except for $-c_{o}\left(Q_{r}+Q_{s}\right)+B-R(e)$ and $V_{r 4}$ are as follows:

(1) The case of $d_{s}+\beta e>Q_{s}$ means that the online demand of the supplier is more than the supply of the supplier whether or not there exists demand transfer from the offline channel. Thus, under this condition, the supplier's expected profit expression is

$$
V_{s 1}=\int_{Q_{s}-\beta e}^{\infty} p_{s} Q_{s} g(y) \mathrm{d} y .
$$

(2) The case of $0<d_{s}+\beta e<Q_{s}, d_{r}+(\alpha-\beta) e>Q_{r}$ means that the online demand of the supplier is less than its supply, but there exists demand transfer from the retailer's offline channel. In this case, the total online demand of the supplier is less than the supply of the supplier if $D_{s}<Q_{s}$. If $D_{s}>Q_{s}$, the total online demand of the supplier is more than the supply of the supplier. Hence, the supplier's expected profit expression is

$$
\begin{aligned}
V_{s 2}= & \int_{Q_{r}-(\alpha-\beta) e}^{\left(\left(Q_{s}-\beta e\right) / K_{r}\right)+Q_{r}-(\alpha-\beta) e} \int_{0}^{Q_{s}-\beta e-K_{r}\left(x+(\alpha-\beta) e-Q_{r}\right)} p_{s}\left(y+\beta e+K_{r}\left(x+(\alpha-\beta) e-Q_{r}\right)\right) g(y) f(x) \mathrm{d} y \mathrm{~d} x \\
& +\int_{Q_{r}-(\alpha-\beta) e}^{\left(\left(Q_{s}-\beta e\right) / K_{r}\right)+Q_{r}-(\alpha-\beta) e} \int_{0}^{Q_{s}-\beta e-K_{r}\left(x+(\alpha-\beta) e-Q_{r}\right)} v\left(Q_{s}-y-\beta e-K_{r}\left(x+(\alpha-\beta) e-Q_{r}\right)\right) g(y) f(x) \mathrm{d} y \mathrm{~d} x \\
& +\int_{Q_{r}-(\alpha-\beta) e}^{\left(\left(Q_{s}-\beta e\right) / K_{r}\right)+Q_{r}-(\alpha-\beta) e} \int_{Q_{s}-\beta e-K_{r}\left(x+(\alpha-\beta) e-Q_{r}\right)}^{Q_{s}-\beta e} p_{s} Q_{s} g(y) f(x) \mathrm{d} y \mathrm{~d} x .
\end{aligned}
$$

(3) The case of $0<d_{s}+\beta e<Q_{s}, 0<d_{r}+(\alpha-\beta) e<Q_{r}$ means that the online demand of the supplier is less than its supply, and there is no transfer from the retailer's offline channel. In this case, the total online demand of the supplier is less than the supply of the supplier if $D_{s}<Q_{s}$. If $D_{s}>Q_{s}$, the total online demand of the supplier is more than the supply of the supplier. Thus, the supplier's expected profit expression is 


$$
\begin{aligned}
V_{s 3}= & \int_{0}^{Q_{r}-(\alpha-\beta) e} \int_{0}^{Q_{s}-\beta e} p_{s}(y+\beta e) g(y) f(x) \mathrm{d} y \mathrm{~d} x \\
& +\int_{0}^{Q_{r}-(\alpha-\beta) e} \int_{0}^{Q_{s}-\beta e} v\left(Q_{s}-y-\beta e\right) g(y) f(x) \mathrm{d} y \mathrm{~d} x .
\end{aligned}
$$

Finally, the expression of the supplier's total expected profit can be as follows:

$$
\begin{aligned}
\pi_{s}^{d}= & -c_{o}\left(Q_{r}+Q_{s}\right)+B-R(e)+V_{s 1}+V_{s 2}+V_{s 3}+V_{r 4} \\
= & p_{s} Q_{s}+\left(w Q_{r}+R(e)-B\right)(1+I)-c_{o}\left(Q_{r}+Q_{s}\right)+B-R(e) \\
& -\left(p_{s}-v\right) \int_{0}^{Q_{r}-(\alpha-\beta) e} \int_{0}^{Q_{s}-\beta e}\left(Q_{s}-y-\beta e\right) g(y) f(x) \mathrm{d} y \mathrm{~d} x \\
& -\left(p_{s}-v\right) \int_{Q_{r}-(\alpha-\beta) e}^{\left(\left(Q_{s}-\beta e\right) / K_{r}\right)+Q_{r}-(\alpha-\beta) e} \int_{0}^{Q_{s}-\beta e-K_{r}\left(x+(\alpha-\beta) e-Q_{r}\right)}\left(Q_{s}-y-\beta e-K_{r}\left(x+(\alpha-\beta) e-Q_{r}\right)\right) g(y) f(x) \mathrm{d} y \mathrm{~d} x \\
& +\int_{Q_{s}-\beta e}^{\left(\left(Q_{r}-(\alpha-\beta) e\right) / K_{s}\right)+Q_{s}-\beta e} \int_{0}^{z-(\alpha-\beta) e-K_{s}\left(y+\beta e-Q_{s}\right)}\left[v Q_{r}+\left(p_{r}-v\right)\left(x+(\alpha-\beta) e+K_{s}\left(y+\beta e-Q_{s}\right)\right)\right] g(y) f(x) \mathrm{d} y \mathrm{~d} x \\
& +\int_{0}^{Q_{s}-\beta e} \int_{0}^{z-(\alpha-\beta) e}\left[v Q_{r}+\left(p_{r}-v\right)(x+(\alpha-\beta) e)\right] g(y) f(x) \mathrm{d} y \mathrm{~d} x \\
& -\left(w Q_{r}+R(e)-B\right)(1+I) \int_{0}^{Q_{s}-\beta e} \int_{0}^{z-(\alpha-\beta) e} g(y) f(x) \mathrm{d} y \mathrm{~d} x \\
& -\left(w Q_{r}+R(e)-B\right)(1+I) \int_{Q_{s}-\beta e}^{\left(\left(Q_{r}-(\alpha-\beta) e\right) / K_{s}\right)+Q_{s}-\beta e} \int_{0}^{z-(\alpha-\beta) e-K_{s}\left(y+\beta e-Q_{s}\right)} g(y) f(x) \mathrm{d} y \mathrm{~d} x .
\end{aligned}
$$

In the following, the optimal solutions of the retailer and the supplier in the decentralized system will be analyzed by using the reverse derivation method. Firstly, for a given sales effort level of the retailer, the retailer's optimal order quantity and the supplier's optimal inventory level can be obtained. Then, the conditions of the retailer's optimal sales effort level are investigated.

With a given sales effort level $L(1+I)$, the first-order partial derivatives of the retailer $Q_{r}^{d}$ and the supplier $Q_{s}^{d}$ are as follows:

$$
\begin{aligned}
F_{r}^{d}= & \frac{\partial \pi_{r}^{d}}{\partial Q_{r}}=p_{r}-w(1+I)-p_{r} \int_{0}^{Q_{s}-\beta e} \int_{0}^{Q_{r}-(\alpha-\beta) e} f(x) g(y) \mathrm{d} x \mathrm{~d} y \\
& -p_{r} \int_{Q_{s}-\beta e}^{\left(\left(Q_{r}-(\alpha-\beta) e\right) / K_{s}\right)+Q_{s}-\beta e} \int_{0}^{Q_{r}-(\alpha-\beta) e-K_{s}\left(y+\beta e-Q_{s}\right)} f(x) g(y) \mathrm{d} x \mathrm{~d} y \\
& +v \int_{Q_{s}-\beta e}^{\left(\left(Q_{r}-(\alpha-\beta) e\right) / K_{s}\right)+Q_{s}-\beta e} \int_{z-(\alpha-\beta) e-K_{s}\left(y+\beta e-Q_{s}\right)}^{Q_{r}-(\alpha-\beta) e-K_{s}\left(y+\beta e-Q_{s}\right)} f(x) g(y) \mathrm{d} x \mathrm{~d} y \\
& +v \int_{0}^{Q_{s}-\beta e} \int_{z-(\alpha-\beta) e}^{Q_{r}-(\alpha-\beta) e} f(x) g(y) \mathrm{d} x \mathrm{~d} y \\
& +w(1+I) \int_{0}^{Q_{s}-\beta e} \int_{0}^{z-(\alpha-\beta) e} f(x) g(y) \mathrm{d} x \mathrm{~d} y \\
& +w(1+I) \int_{Q_{s}-\beta e}^{\left(\left(Q_{r}-(\alpha-\beta) e\right) / K_{s}\right)+Q_{s}-\beta e} \int_{0}^{z-(\alpha-\beta) e-K_{s}\left(y+\beta e-Q_{s}\right)} f(x) g(y) \mathrm{d} x \mathrm{~d} y \\
= & 0 .
\end{aligned}
$$




$$
\begin{aligned}
F_{s}^{d}= & \frac{\partial \pi_{s}^{d}}{\partial Q_{s}}=p_{s}-c_{o} \\
& -\left(p_{s}-v\right)\left[\int_{0}^{Q_{r}-(\alpha-\beta) e} \int_{0}^{Q_{s}-\beta e} g(y) f(x) \mathrm{d} y \mathrm{~d} x\right. \\
& \left.+\int_{Q_{r}-(\alpha-\beta) e}^{\left(\left(Q_{s}-\beta e\right) / K_{r}\right)+Q_{r}-(\alpha-\beta) e} \int_{0}^{Q_{s}-\beta e-K_{r}\left(x+(\alpha-\beta) e-Q_{r}\right)} g(y) f(x) \mathrm{d} y \mathrm{~d} x\right] \\
& -\left(p_{r}-v\right) K_{s} \int_{Q_{s}-\beta e}^{\left(\left(Q_{r}-(\alpha-\beta) e\right) / K_{s}\right)+Q_{s}-\beta e} \int_{0}^{z-(\alpha-\beta) e-K_{s}\left(y+\beta e-Q_{s}\right)} g(y) f(x) \mathrm{d} y \mathrm{~d} x \\
= & 0 .
\end{aligned}
$$

Proposition 1. Under the decentralized decision, for any given sales effort level $e$, if $\left(p_{r}-v\right) K_{s}>w(1+I)-v$, the supplier's expected profit $\pi_{s}$ and the retailer's expected profit $\pi_{r}$ are strictly jointly concave in $Q_{s}$ and $Q_{r}$.

The proofs of Proposition 1, and the following propositions and lemmas are presented in Appendix. Proposition 1 proves that for any given sales effort level $e$, the optimal values of $Q_{s}$ and $Q_{r}$ can be found by using the first-order conditions.

Proposition 2. The optimal sales effort level of the retailer in the decentralized scenario satisfies the following equation:

$$
\frac{\partial \pi_{r}^{d}}{\partial Q_{r}} \frac{\mathrm{d} Q_{r}(e)}{\mathrm{d} e}+\frac{\partial \pi_{r}^{d}}{\partial Q_{s}} \frac{\mathrm{dQ}_{s}(e)}{\mathrm{d} e}+\frac{\partial \pi_{r}^{d}}{\partial e}=0
$$

Among them,

$$
\frac{\mathrm{d} Q_{r}(e)}{\mathrm{d} e}=-\frac{1}{J}\left|\begin{array}{ll}
\frac{\partial F_{r}^{d}}{\partial e} & \frac{\partial F_{r}^{d}}{\partial Q_{s}} \\
\frac{\partial F_{s}^{d}}{\partial e} & \frac{\partial F_{s}^{d}}{\partial Q_{s}}
\end{array}\right|=-\frac{1}{J}\left(\frac{\partial^{2} \pi_{r}^{d}}{\partial Q_{r} \partial e} \frac{\partial^{2} \pi_{s}^{d}}{\partial Q_{s}^{2}}-\frac{\partial^{2} \pi_{r}^{d}}{\partial Q_{r} \partial Q_{s}} \frac{\partial^{2} \pi_{s}^{d}}{\partial Q_{s} \partial e}\right),
$$

$$
\frac{\mathrm{d}_{s}(e)}{\mathrm{d} e}=-\frac{1}{J}\left|\begin{array}{ll}
\frac{\partial F_{r}^{d}}{\partial Q_{r}} & \frac{\partial F_{r}^{d}}{\partial e} \\
\frac{\partial F_{s}^{d}}{\partial Q_{r}} & \frac{\partial F_{s}^{d}}{\partial e}
\end{array}\right|=-\frac{1}{J}\left(\frac{\partial^{2} \pi_{r}^{d}}{\partial Q_{r}^{2}} \frac{\partial^{2} \pi_{s}^{d}}{\partial Q_{s} \partial e}-\frac{\partial^{2} \pi_{r}^{d}}{\partial Q_{r} \partial e} \frac{\partial^{2} \pi_{s}^{d}}{\partial Q_{s} \partial Q_{r}}\right)
$$

In the end, according to Proposition 1, the expressions of $Q_{r}^{d}(e)$ and $Q_{s}^{d}(e)$ can be obtained by integrating formulas (13) and (14) and then be taken into formula (15) based on Proposition 2, so as to get $e^{d *}$. Finally, $Q_{r}^{d *}$ and $Q_{s}^{d *}$ can be derived by taking $e^{d *}$ into $Q_{r}^{d}(e)$ and $Q_{s}^{d}(e)$.

4.2. Dual-Channel Supply Chain Model under the Centralized Decision-Making. In the centralized system, supply chain members make decisions with the goal of optimal overall profit.

Hence, the overall expected profit of supply chain in the centralized system is 


$$
\begin{aligned}
\prod= & \pi_{r}^{d}+\pi_{s}^{d} \\
= & \left(p_{r}-c_{o}\right) Q_{r}+\left(p_{s}-c_{o}\right) Q_{s}-\frac{\eta e^{2}}{2} \\
& -\left(p_{r}-v\right) \int_{0}^{Q_{s}-\beta e} \int_{0}^{Q_{r}-(\alpha-\beta) e}\left(Q_{r}-x-(\alpha-\beta) e\right) f(x) g(y) \mathrm{d} x \mathrm{~d} y \\
& -\left(p_{s}-v\right) \int_{0}^{Q_{r}-(\alpha-\beta) e} \int_{0}^{Q_{s}-\beta e}\left(Q_{s}-y-\beta e\right) g(y) f(x) \mathrm{d} y \mathrm{~d} x \\
& -\left(p_{r}-v\right) \int_{Q_{s}-\beta e}^{\left(\left(Q_{r}-(\alpha-\beta) e\right) / K_{s}\right)+Q_{s}-\beta e} \int_{0}^{Q_{r}-(\alpha-\beta) e-K_{s}\left(y+\beta e-Q_{s}\right)}\left(Q_{r}-x-(\alpha-\beta) e-K_{s}\left(y+\beta e-Q_{s}\right)\right) f(x) g(y) \mathrm{d} x \mathrm{~d} y \\
& -\left(p_{s}-v\right) \int_{Q_{r}-(\alpha-\beta) e}^{\left(\left(Q_{s}-\beta e\right) / K_{r}\right)+Q_{r}-(\alpha-\beta) e} \int_{0}^{Q_{s}-\beta e-K_{r}\left(x+(\alpha-\beta) e-Q_{r}\right)}\left(Q_{s}-y-\beta e-K_{r}\left(x+(\alpha-\beta) e-Q_{r}\right)\right) g(y) f(x) \mathrm{d} y \mathrm{~d} x .
\end{aligned}
$$

Under the centralized decision, with the given sales effort level $e^{c}$, the first-order partial derivatives of the overall profit of the supply chain with respect to $Q_{r}^{c}$ and $Q_{s}^{c}$ are as follows:

$$
\begin{aligned}
F_{r}^{c}= & \frac{\partial \prod}{\partial Q_{r}}=p_{r}-c_{o} \\
& -\left(p_{r}-v\right)\left[\int_{0}^{Q_{s}-\beta e} \int_{0}^{Q_{r}-(\alpha-\beta) e} f(x) g(y) \mathrm{d} x \mathrm{~d} y+\int_{Q_{s}-\beta e}^{\left(\left(Q_{r}-(\alpha-\beta) e\right) / K_{s}\right)+Q_{s}-\beta e} \int_{0}^{Q_{r}-(\alpha-\beta) e-K_{s}\left(y+\beta e-Q_{s}\right)} f(x) g(y) \mathrm{d} x \mathrm{~d} y\right] \\
& -K_{r}\left(p_{s}-v\right) \int_{Q_{r}-(\alpha-\beta) e}^{\left(\left(Q_{s}-\beta e\right) / K_{r}\right)+Q_{r}-(\alpha-\beta) e} \int_{0}^{Q_{s}-\beta e-K_{r}\left(x+(\alpha-\beta) e-Q_{r}\right)} g(y) f(x) \mathrm{d} y \mathrm{~d} x \\
= & 0, \\
F_{s}^{c}= & \frac{\partial}{\partial Q_{s}}=p_{s}-c_{o} \\
& -\left(p_{s}-v\right)\left[\int_{0}^{Q_{r}-(\alpha-\beta) e} \int_{0}^{Q_{s}-\beta e} g(y) f(x) \mathrm{d} y \mathrm{~d} x+\int_{Q_{r}-(\alpha-\beta) e}^{\left(\left(Q_{s}-\beta e\right) / K_{r}\right)+Q_{r}-(\alpha-\beta) e} \int_{0}^{Q_{s}-\beta e-K_{r}\left(x+(\alpha-\beta) e-Q_{r}\right)} g(y) f(x) \mathrm{d} y \mathrm{~d} x\right] \\
& -K_{s}\left(p_{r}-v\right) \int_{Q_{s}-\beta e}^{\left(\left(Q_{r}-(\alpha-\beta) e\right) / K_{s}\right)+Q_{s}-\beta e} \int_{0}^{Q_{r}-(\alpha-\beta) e-K_{s}\left(y+\beta e-Q_{s}\right)} f(x) g(y) \mathrm{d} x \mathrm{~d} y \\
= & 0 .
\end{aligned}
$$

Proposition 3. Under the centralized decision, the overall expected profit of centralized dual-channel supply chain $\prod$ is jointly concave in $Q_{r}^{c}$ and $Q_{s}^{c}$, but not jointly concave in $Q_{r}^{c}, Q_{s}^{c}$ and $e^{c}$.

Proposition 4. The optimal sales effort level of retailer in the centralized system satisfies the following equation:

$$
\begin{array}{r}
\frac{\partial \prod}{\partial Q_{r}} \frac{\mathrm{d} Q_{r}(e)}{\mathrm{d} e}+\frac{\partial \prod}{\partial Q_{s}} \frac{\mathrm{d} Q_{s}(e)}{\mathrm{d} e}+\frac{\partial \prod}{\partial e}=0, \\
\frac{\mathrm{d} Q_{r}(e)}{\mathrm{d} e}=-\frac{1}{\widehat{J}}\left(\frac{\partial^{2} \prod}{\partial Q_{r} \partial e} \frac{\partial^{2} \prod}{\partial Q_{s}^{2}}-\frac{\partial^{2} \prod}{\partial Q_{r} \partial Q_{s}} \frac{\partial^{2} \prod}{\partial Q_{s} \partial e}\right), \\
\frac{\mathrm{d}_{s}(e)}{\mathrm{d} e}=-\frac{1}{\widehat{J}}\left(\frac{\partial^{2} \prod}{\partial Q_{r}^{2}} \frac{\partial^{2} \prod}{\partial Q_{s} \partial e}-\frac{\partial^{2} \prod}{\partial Q_{r} \partial e} \frac{\partial^{2} \prod}{\partial Q_{s} \partial Q_{r}}\right) .
\end{array}
$$


Based on Proposition 4, the following lemmas can be obtained.

Lemma 1. Both $Q_{r}^{c}$ and $Q_{s}^{c}$ are monotone increasing functions of sales effort coefficient $e^{c}$ under the centralized decision.

To get more managerial implications, this work assumes that the market demand in two channels follow uniform distribution in the following lemma.

Lemma 2. When the demand is uniformly distributed, $d_{r} \sim U(0, \theta), d_{s} \sim U(0, \theta)$, the expected profit $\prod$ of the whole supply chain is a strict concave function of the retailer's sales effort level $e^{c}$.

Finally, the optimal sales effort level of the retailer can be obtained by Lemma 2 and can be expressed as $e^{c *}=\left(\left(p_{r}-c_{o}\right)(\alpha-\beta)+\left(p_{s}-c_{o}\right) \beta\right) / \eta$. Next, according to Proposition 3 and Lemma 2 , bringing $e^{c *}$ into formulas (18) and (19), the supplier's optimal inventory level $Q_{s}^{c *}$ and the retailer's optimal order quantity $Q_{r}^{c *}$ in the centralized system can be obtained by combining formulas (18) and (19).

It is known that centralized decision can achieve higher overall profit of supply chain than decentralized decision, but it does not provide some mechanism to allocate profit. Hence, it is fundamental to coordinate the supply chain with specific contracts in order to make the members of the dualchannel supply chain reach Pareto optimization.

\section{Coordination Contract}

This section proposes a coordination contract: the supplier partially buys back the retailer's surplus inventory with a certain proportion $(u)$ at the wholesale price $w$. And the coordination method is based on the research of Zhong et al. [49].

In this case, $0<u \leq 1$, and the retailer's critical value of demand and expected profit of the retailer and the supplier can be expressed as follows:

$$
\begin{aligned}
& z=\frac{\left(w Q_{r}+R(e)-B\right)(1+I)-Q_{r}[(1-u) v+u w]}{p_{r}-u w-(1-u) v}, \\
& \pi_{r}^{u}=p_{r} Q_{r}-\left(w Q_{r}+R(e)-B\right)(1+I)-B \\
& -p_{r} Q_{r} \int_{0}^{Q_{s}-\beta e} \int_{0}^{Q_{r}-(\alpha-\beta) e} f(x) g(y) \mathrm{d} x \mathrm{~d} y \\
& -p_{r} Q_{r} \int_{Q_{s}-\beta e}^{\left(\left(Q_{r}-(\alpha-\beta) e\right) / K_{s}\right)+Q_{s}-\beta e} \int_{0}^{Q_{r}-(\alpha-\beta) e-K_{s}\left(y+\beta e-Q_{s}\right)} f(x) g(y) \mathrm{d} x \mathrm{~d} y \\
& +\int_{Q_{s}-\beta e}^{\left(\left(Q_{r}-(\alpha-\beta) e\right) / K_{s}\right)+Q_{s}-\beta e} \int_{z-(\alpha-\beta) e-K_{s}\left(y+\beta e-Q_{s}\right)}^{Q_{r}-(\alpha-\beta) e-K_{s}\left(y+\beta e-Q_{s}\right)}\left[((1-u) v+u w) Q_{r}+\left(p_{r}-(1-u) v-u w\right)(x+(\alpha-\beta) e\right. \\
& \left.\left.+K_{s}\left(y+\beta e-Q_{s}\right)\right)\right] f(x) g(y) \mathrm{d} x \mathrm{~d} y \\
& +\int_{0}^{Q_{s}-\beta e} \int_{z-(\alpha-\beta) e}^{Q_{r}-(\alpha-\beta) e}\left[((1-u) v+u w) Q_{r}+\left(p_{r}-(1-u) v-u w\right)(x+(\alpha-\beta) e)\right] f(x) g(y) \mathrm{d} x \mathrm{~d} y \\
& +\left(w Q_{r}+R(e)-B\right)(1+I) \int_{0}^{Q_{s}-\beta e} \int_{0}^{z-(\alpha-\beta) e} f(x) g(y) \mathrm{d} x \mathrm{~d} y \\
& +\left(w Q_{r}+R(e)-B\right)(1+I) \int_{Q_{s}-\beta e}^{\left(\left(Q_{r}-(\alpha-\beta) e\right) / K_{s}\right)+Q_{s}-\beta e} \int_{0}^{z-(\alpha-\beta) e-K_{s}\left(y+\beta e-Q_{s}\right)} f(x) g(y) \mathrm{d} x \mathrm{~d} y \text {, }
\end{aligned}
$$




$$
\begin{aligned}
\pi_{s}^{u}= & p_{s} Q_{s}+\left(w Q_{r}+R(e)-B\right)(1+I)-c_{o}\left(Q_{r}+Q_{s}\right)+B-R(e) \\
& -\left(p_{s}-v\right) \int_{0}^{Q_{r}-(\alpha-\beta) e} \int_{0}^{Q_{s}-\beta e}\left(Q_{s}-y-\beta e\right) g(y) f(x) \mathrm{d} y \mathrm{~d} x \\
& -\left(p_{s}-v\right) \int_{Q_{r}-(\alpha-\beta) e}^{\left(\left(Q_{s}-\beta e\right) / K_{r}\right)+Q_{r}-(\alpha-\beta) e} \int_{0}^{Q_{s}-\beta e-K_{r}\left(x+(\alpha-\beta) e-Q_{r}\right)}\left(Q_{s}-y-\beta e-K_{r}\left(x+(\alpha-\beta) e-Q_{r}\right)\right) g(y) f(x) \mathrm{d} y \mathrm{~d} x \\
& \quad+\int_{Q_{s}-\beta e}^{\left(\left(Q_{r}-(\alpha-\beta) e\right) / K_{s}\right)+Q_{s}-\beta e} \int_{0}^{z-(\alpha-\beta) e-K_{s}\left(y+\beta e-Q_{s}\right)}\left[((1-u) v+u w) Q_{r}+\left(p_{r}-(1-u) v-u w\right)(x+(\alpha-\beta) e\right. \\
& \left.\left.+K_{s}\left(y+\beta e-Q_{s}\right)\right)\right] f(x) g(y) \mathrm{d} x \mathrm{~d} y \\
& +\int_{0}^{Q_{s}-\beta e} \int_{0}^{z-(\alpha-\beta) e}\left[((1-u) v+u w) Q_{r}+\left(p_{r}-(1-u) v-u w\right)(x+(\alpha-\beta) e)\right] f(x) g(y) \mathrm{d} x \mathrm{~d} y \\
& -(u w-u v) \int_{Q_{s}-\beta e}^{\left(\left(Q_{r}-(\alpha-\beta) e\right) / K_{s}\right)+Q_{s}-\beta e} \int_{0}^{Q_{r}-(\alpha-\beta) e-K_{s}\left(y+\beta e-Q_{s}\right)}\left[Q_{r}-x-(\alpha-\beta) e-K_{s}\left(y+\beta e-Q_{s}\right)\right] f(x) g(y) \mathrm{d} x \mathrm{~d} y \\
& -(u w-u v) \int_{0}^{Q_{s}-\beta e} \int_{0}^{Q_{r}-(\alpha-\beta) e}\left[Q_{r}-x-(\alpha-\beta) e\right] f(x) g(y) \mathrm{d} x \mathrm{~d} y \\
& -\left(w Q_{r}+R(e)-B\right)(1+I) \int_{0}^{Q_{s}-\beta e} \int_{0}^{z-(\alpha-\beta) e} f(x) g(y) \mathrm{d} x \mathrm{~d} y \\
& -\left(w Q_{r}+R(e)-B\right)(1+I) \int_{Q_{s}-\beta e}^{\left(\left(Q_{r}-(\alpha-\beta) e\right) / K_{s}\right)+Q_{s}-\beta e} \int_{0}^{z-(\alpha-\beta) e-K_{s}\left(y+\beta e-Q_{s}\right)} f(x) g(y) \mathrm{d} x \mathrm{~d} y .
\end{aligned}
$$

For the purpose of achieving coordination, the following conditions should be satisfied:

$$
\begin{aligned}
\pi_{r}^{u}\left(Q_{r}^{c *}, e^{c *}\right)+\pi_{s}^{u}\left(Q_{s}^{c *}, e^{c *}\right) & =\prod\left(Q_{r}^{c *}, Q_{s}^{c *}, e^{c *}\right), \\
\pi_{r}^{u}\left(Q_{r}^{c *}, e^{c *}\right) & \geq \pi_{r}^{d}\left(Q_{r}^{d *}, e^{d *}\right), \\
\pi_{s}^{u}\left(Q_{s}^{c *}, e^{c *}\right) & \geq \pi_{s}^{d}\left(Q_{s}^{d *}, e^{d *}\right), \\
z^{u} & \geq 0 .
\end{aligned}
$$

Finally, the range of $u$ can be obtained. Similarly, if the value of $u$ is greater than 1 , it means that the supply chain cannot be coordinated by a single partial buyback contract, and it needs to be coordinated with other contracts. However, the next numerical analysis shows that a single partial buyback contract can coordinate the dual-channel supply chain system.

\section{Numerical Analysis}

Referring to Yang et al. [33], the related parameters are assigned as follows: the potential market size of traditional retail channel and online channel is uniformly distributed, $d_{r} \sim U(0, \theta), d_{s} \sim U(0, \theta)$. Retailer's initial capital is $B=\$ 50,000$. Trade credit rate $I=0.05$. Unit product price of traditional retail channel $p_{r}=\$ 650$. Unit product price of online channel $p_{s}=\$ 645$. Supplier's unit production cost $c_{o}=\$ 350$. The wholesale price of supplier's unit product $w=\$ 480$. The residual value of remaining inventory $v=\$ 200$. Elasticity coefficient of market demand to sales effort level of offline channel $\alpha=20$. Cost coefficient of sales effort $\eta=1000$. Supplier free riding coefficient $\beta=10$. Consumer switching rate of the retailer's offline channel $K_{r}=0.2$. Consumer switching rate of the supplier's online channels $K_{s}=0.2$. In this case, according to Proposition 1, it holds for $|J|=\left(\partial^{2} \pi_{r}^{d} / \partial Q_{r}^{2}\right)\left(\partial^{2} \pi_{s}^{d} / \partial Q_{s}^{2}\right)-\left(\partial^{2} \pi_{r}^{d} / \partial Q_{r} \partial Q_{s}\right)$ $\left(\partial^{2} \pi_{s}^{d} / \partial Q_{s} \partial Q_{r}\right)>0$. That is, for any given sales effort level $e^{d}$, the supplier's total expected profit $\pi_{s}^{d}$ and the retailer's total expected profit $\pi_{r}^{d}$ are jointly concave in $Q_{s}^{d}$ and $Q_{r}^{d}$.

Hence, based on the above theoretical analysis, the optimal order quantities in the decentralized and centralized systems are $Q_{r}^{d *}=348.1519$ and $Q_{r}^{c *}=569.5954$; the corresponding optimal inventory levels are $Q_{s}^{d *}=566.2159$ and $Q_{s}^{c *}=564.5006$; the corresponding optimal sales effort levels are $e^{d *}=1.3905$ and $e^{c *}=5.95$; the corresponding optimal expected profit is $\pi_{r}^{d}=\$ 25087.16$ and $\pi_{s}^{d}=\$ 138395.26$, and the optimal total expected profit is $\Pi=\$ 181434.60$.

6.1. Sensitivity Analysis. Referring to $[33,35]$ and combining with the innovation points of this study, this section mainly investigates the impacts of the supplier's wholesale price, offline sales price, online sales price, consumer switching rate, and free riding on the optimal sales effort level, the optimal order quantity, the optimal inventory level, the optimal expected profit of the retailer and the supplier in the decentralized system, and the optimal total expected profit, respectively.

Table 3 shows that (1) with the increase of the supplier's wholesale price $w$, the optimal sales effort level $e^{d *}$, the optimal order quantity $Q_{r}^{d *}$, and the expected offline retailer profit $\pi_{r}^{d}$ under the decentralized decision-making will decrease, while the optimal inventory level $Q_{s}^{d *}$ and expected online supplier profit $\pi_{s}^{d}$ will increase; (2) for a given wholesale price $w$, the optimal total expected profit, the optimal sales effort level, and the optimal order quantity in the centralized system are all superior to those in the decentralized system; and (3) with the increase of the whole sale price $w$, the optimal online inventory level $Q_{s}^{d *}$ under the decentralized scenario will raise gradually and exceed the optimal inventory level $Q_{s}^{c *}$ under the centralized scenario.

From Table 4, it can be found that (1) under the decentralized decision-making, with the increase of offline 
sales price $p_{r}$, the optimal sales effort $e^{d *}$, the optimal order quantity $Q_{r}^{d *}$, the expected offline retailer profit $\pi_{r}^{d}$, and the optimal online supplier profit $Q_{s}^{d *}$ will increase, while the optimal inventory level decreases; (2) under centralized decision-making, with the increase of offline sales price $p_{r}$, the optimal order quantity $Q_{r}^{c *}$, the optimal sales effort level $e^{c *}$, and total expected supply chain profit will rise gradually, while the inventory level $Q_{s}^{c *}$ decreases; and (3) For a given offline sales price $p_{r}$, the total expected supply chain profit, the optimal sales effort level, and the optimal order quantity in centralized system are all more than those in decentralized system, while the optimal inventory level in centralized system is less than that in the decentralized system.

It can be observed from Table 5 that (1) with the raise of the online sales price $p_{s}$ in the decentralized system, the optimal order quantity $Q_{r}^{d *}$ and the optimal offline profit $\pi_{r}^{d}$ will reduce slightly, while the optimal inventory level $Q_{s}^{d *}$ and the optimal online expected profit $\pi_{s}^{d}$ will increase; (2) with the raise of the online sales price $p_{s}$ in the centralized system, the optimal sales effort level $e^{c *}$, the optimal inventory level $Q_{s}^{c *}$, and total expect profit $\prod$ will increase, while the optimal offline order quantity $Q_{r}^{c *}$ decreases; and (3) for a given online sales price $p_{s}$, the total expected supply chain profit, the optimal sales effort level, and the optimal order quantity under the centralized decision-making are all higher than those under the decentralized decision-making, while the optimal online inventory level $Q_{s}^{c *}$ under the centralized decision-making is less than $Q_{s}^{d *}$ under the decentralized decision-making.

Table 6 suggests that (1) in the decentralized system, with the increase of $K_{r}$, the optimal order quantity $Q_{r}^{d *}$, and the optimal offline profit $\pi_{r}^{d}$ will decrease slightly, while the optimal inventory level $Q_{s}^{d *}$ and the optimal online profit $\pi_{s}^{d}$ will increase; (2) in the centralized system, with the increase of $K_{r}$, the optimal online inventory level $Q_{s}^{c *}$ and the total expected supply chain profit $\prod$ will increase, while the optimal offline inventory $Q_{r}^{c *}$ will decrease; and (3) for a given offline consumer switching rate $K_{r}$, the total expected supply chain profit, the optimal sales effort level, the optimal order quantity, and the optimal inventory level in the centralized supply chain are all higher than those in the decentralized supply chain.

It can be concluded from Table 7 that (1) with the raise of $K_{s}$ in the decentralized supply chain, the optimal order quantity $Q_{r}^{d *}$, the optimal offline profit $\pi_{r}^{d}$, and the optimal online profit $\pi_{s}^{d}$ all increase; (2) with the raise of $K_{s}$ in the centralized supply chain, the optimal order quantity $Q_{r}^{c *}$ and the total expected supply chain profit both increase, but the optimal inventory level $Q_{s}^{c *}$ decreases; and (3) for a given online consumer switching rate $K_{s}$, the total expected supply chain profit, the optimal sales effort level, and the optimal order quantity under the centralized decision-making are all higher than those under the decentralized decision-making, while the optimal online inventory level $Q_{s}^{c *}$ under the centralized decision-making is less than $Q_{s}^{d *}$ under the decentralized decision-making.

Table 8 demonstrates that (1) under the decentralized scenario, with the increase of free riding $\beta$, the optimal order quantity $Q_{r}^{d *}$, the optimal sales effort level $e^{d *}$, the optimal offline profit $\pi_{r}^{d}$ and the optimal online profit $\pi_{s}^{d}$ will decrease, while the optimal online inventory level $Q_{s}^{d *}$ will increase; (2) under the centralized scenario, with the increase of $\beta$, the optimal sales effort level $e^{c *}$, the optimal order quantity $Q_{r}^{c *}$, and the total expected supply chain profit will decrease, while the optimal online inventory level $Q_{s}^{c *}$ will increase; and (3) for a given free riding coefficient $\beta$, the total expected supply chain profit, the optimal sales effort level, and the optimal order quantity under the centralized are more than those under the decentralized scenario.

6.2. Coordination Analysis. It is well known that the centralized decision-making cannot provide a mechanism to share the total expected profit for each supply chain member. This subsection develops one partial buyback contract so as to make the supplier and the retailer achieve the Pareto optimization. The supplier partially buys back the retailer's surplus inventory according to a certain proportion $(u)$ at the wholesale price $w$.

To achieve the coordination, the following constraints should be satisfied:

$$
\begin{aligned}
\pi_{r}^{u}\left(Q_{r}^{c *}, e^{c *}\right)+\pi_{s}^{u}\left(Q_{s}^{c *}, e^{c *}\right) & =\prod\left(Q_{r}^{c *}, Q_{s}^{c *}, e^{c *}\right), \\
\pi_{r}^{u}\left(Q_{r}^{c *}, e^{c *}\right) & \geq \pi_{r}^{d}\left(Q_{r}^{d *}, e^{d *}\right), \\
\pi_{s}^{u}\left(Q_{s}^{c *}, e^{c *}\right) & \geq \pi_{s}^{d}\left(Q_{s}^{d *}, e^{d *}\right), \\
z^{u} & \geq 0 .
\end{aligned}
$$

Hence, it is easy to obtain that $0.622426<u<0.873072$. Table 9 lists the offline retailer and online supplier expected profits with some values of partial buyback rate $u$, and Figure 3 shows the impact of $u$ on the change rate of the offline and online profits.

It can be seen that the increase of the supplier's partial buyback rate $u$ will raise the growth rate of the offline retailer's profit and reduce the growth rate of the online supplier's profit. Hence, the partial buyback contract can stimulate the offline retailer to cooperate with the online supplier. The final value of partial buyback rate depends on their agreement.

\section{Conclusion and Managerial Implications}

This study develops a dual-channel supply chain model, which includes an online supplier with sufficient funds and an offline retailer with capital constraints, and the supplier provides trade credit financing to the retailer. Based on it, this work investigates the influence of "free riding" behavior and consumer switching behavior on the retailer's ordering decision and the supplier's inventory decision with the stochastic demand. Subsequently, this research analyzes the impacts of the supplier's wholesale price, online and offline sales prices, consumer switching behavior, and free riding behavior on sales effort level, inventory level, order quantity, and the offline and the online profits under the decentralized and centralized decision-making, respectively. Then, it analyzes the optimal sales effort level, the optimal inventory level, and optimal order quantity, and the optimal offline and 
TABLE 3: Sensitivity analysis of wholesale price $w$.

\begin{tabular}{lccccccccc}
\hline$w$ & $e^{d *}$ & $e^{c *}$ & $Q_{r}^{d *}$ & $Q_{r}^{c *}$ & $Q_{s}^{d *}$ & $Q_{s}^{c *}$ & $\pi_{r}^{d}$ & $\pi_{s}^{d}$ \\
\hline 500 & 1.19 & 5.95 & 302.02 & 569.60 & 570.65 & 564.50 & 18990.23 & 139354.81 \\
480 & 1.39 & 5.95 & 348.15 & 569.60 & 566.22 & 564.50 & 25087.16 & 138395.29 & 181434.60 \\
460 & 1.59 & 5.95 & 387.48 & 569.60 & 563.52 & 564.50 & 31861.89 & 135332.49 \\
440 & 1.79 & 5.95 & 422.64 & 569.60 & 561.97 & 564.50 & 39269.87 & 130711.38 & 181434.60 \\
420 & 1.99 & 5.95 & 455.25 & 569.60 & 561.24 & 564.50 & 47304.32 & 124796.02 & 181434.60 \\
400 & 2.19 & 5.95 & 486.38 & 569.60 & 561.12 & 564.50 & 55981.77 & 117705.30 & 181434.60 \\
\hline
\end{tabular}

TABLE 4: Sensitivity analysis of offline retailer channel sales price $p_{r}$.

\begin{tabular}{|c|c|c|c|c|c|c|c|c|c|}
\hline$p_{r}$ & $e^{d *}$ & $e^{c *}$ & $Q_{r}^{d *}$ & $Q_{r}^{c *}$ & $Q_{s}^{d *}$ & $Q_{s}^{c *}$ & $\pi_{r}^{d}$ & $\pi_{s}^{d}$ & $\prod$ \\
\hline 660 & 1.49 & 6.05 & 364.37 & 578.28 & 564.79 & 563.31 & 27877.33 & 140186.00 & 185590.93 \\
\hline 650 & 1.39 & 5.95 & 348.15 & 569.60 & 566.22 & 564.50 & 25087.16 & 138395.29 & 181434.60 \\
\hline 640 & 1.30 & 5.85 & 330.13 & 560.52 & 567.99 & 565.72 & 22387.88 & 136437.34 & 177318.86 \\
\hline 630 & 1.20 & 5.75 & 309.89 & 551.01 & 570.20 & 566.98 & 19793.62 & 134261.27 & 173246.10 \\
\hline 620 & 1.10 & 5.65 & 286.89 & 541.04 & 572.96 & 568.28 & 17323.13 & 131793.97 & 169218.92 \\
\hline 610 & 1.01 & 5.55 & 260.37 & 530.57 & 576.44 & 569.64 & 15001.85 & 128927.26 & 165240.27 \\
\hline 600 & 0.91 & 5.45 & 229.26 & 519.54 & 580.89 & 571.05 & 12865.41 & 125495.33 & 161313.40 \\
\hline
\end{tabular}

TABLE 5: Sensitivity analysis of online sales price $p_{s}$.

\begin{tabular}{|c|c|c|c|c|c|c|c|c|c|}
\hline$p_{s}$ & $e^{d *}$ & $e^{c *}$ & $Q_{r}^{d *}$ & $Q_{r}^{c *}$ & $Q_{s}^{d *}$ & $Q_{s}^{c *}$ & $\pi_{r}^{d}$ & $\pi_{s}^{d}$ & $\prod$ \\
\hline 655 & 1.39 & 6.05 & 347.93 & 568.42 & 572.38 & 573.41 & 25038.97 & 142319.59 & 185570.04 \\
\hline 645 & 1.39 & 5.95 & 348.15 & 569.60 & 566.22 & 564.50 & 25087.16 & 138395.29 & 181434.60 \\
\hline 635 & 1.39 & 5.85 & 348.39 & 570.80 & 559.77 & 555.18 & 25138.92 & 134494.49 & 177341.09 \\
\hline 625 & 1.39 & 5.75 & 348.65 & 572.05 & 553.01 & 545.40 & 25194.60 & 130618.95 & 173292.04 \\
\hline 615 & 1.39 & 5.65 & 348.93 & 573.34 & 545.92 & 535.14 & 25254.60 & 126770.59 & 169290.25 \\
\hline 605 & 1.39 & 5.55 & 349.23 & 574.69 & 538.47 & 524.35 & 25319.36 & 122951.54 & 165338.85 \\
\hline 595 & 1.39 & 5.45 & 349.56 & 576.10 & 530.65 & 512.98 & 25389.40 & 119164.13 & 161441.35 \\
\hline
\end{tabular}

TABLE 6: Sensitivity analysis of consumer switching rate of the retailer's offline channel $K_{r}$.

\begin{tabular}{|c|c|c|c|c|c|c|c|c|c|}
\hline$K_{r}$ & $e^{d *}$ & $e^{c *}$ & $Q_{r}^{d *}$ & $Q_{r}^{c *}$ & $Q_{s}^{d *}$ & $Q_{s}^{c *}$ & $\pi_{r}^{d}$ & $\pi_{s}^{d}$ & $\prod$ \\
\hline 0.8 & 1.39 & 5.95 & 345.57 & 395.81 & 650.24 & 683.13 & 24535.64 & 158236.33 & 193195.89 \\
\hline 0.7 & 1.39 & 5.95 & 345.93 & 436.89 & 636.12 & 649.01 & 24612.46 & 155226.90 & 190580.98 \\
\hline 0.6 & 1.39 & 5.95 & 346.32 & 470.91 & 622.04 & 623.31 & 24695.42 & 152096.07 & 188296.43 \\
\hline 0.5 & 1.39 & 5.95 & 346.74 & 500.24 & 608.00 & 603.28 & 24784.46 & 148845.61 & 186276.64 \\
\hline 0.4 & 1.39 & 5.95 & 347.18 & 526.04 & 594.02 & 587.42 & 24879.50 & 145477.36 & 184479.33 \\
\hline 0.3 & 1.39 & 5.95 & 347.65 & 549.01 & 580.09 & 574.72 & 24980.43 & 141993.26 & 182873.52 \\
\hline 0.2 & 1.39 & 5.95 & 348.15 & 569.60 & 566.22 & 564.50 & 25087.16 & 138395.29 & 181434.60 \\
\hline
\end{tabular}

TABLE 7: Sensitivity analysis of consumer switching rate of the supplier's online channel $K_{s}$.

\begin{tabular}{|c|c|c|c|c|c|c|c|c|c|}
\hline$K_{s}$ & $e^{d *}$ & $e^{c *}$ & $Q_{r}^{d *}$ & $Q_{r}^{c *}$ & $Q_{s}^{d *}$ & $Q_{s}^{c *}$ & $\pi_{r}^{d}$ & $\pi_{s}^{d}$ & $\prod$ \\
\hline 0.9 & 1.39 & 5.95 & 363.93 & 756.61 & 567.67 & 309.94 & 28506.45 & 140093.56 & 197633.33 \\
\hline 0.8 & 1.39 & 5.95 & 361.98 & 698.17 & 565.53 & 375.17 & 28080.44 & 139968.15 & 194155.49 \\
\hline 0.7 & 1.39 & 5.95 & 359.89 & 659.84 & 563.96 & 421.59 & 27622.86 & 139800.62 & 191266.35 \\
\hline 0.6 & 1.39 & 5.95 & 357.66 & 631.78 & 563.02 & 458.98 & 27138.89 & 139591.65 & 188776.66 \\
\hline 0.5 & 1.39 & 5.95 & 355.34 & 610.31 & 562.76 & 490.70 & 26635.18 & 139343.12 & 186596.15 \\
\hline 0.4 & 1.39 & 5.95 & 352.95 & 593.51 & 563.20 & 518.34 & 26119.56 & 139058.05 & 184669.91 \\
\hline 0.3 & 1.39 & 5.95 & 350.54 & 580.21 & 564.35 & 542.75 & 25600.62 & 138740.49 & 182959.33 \\
\hline 0.2 & 1.39 & 5.95 & 348.15 & 569.60 & 566.22 & 564.50 & 25087.16 & 138395.29 & 181434.60 \\
\hline 0.1 & 1.39 & 5.95 & 345.82 & 561.09 & 568.75 & 583.98 & 24587.64 & 138027.76 & 180071.36 \\
\hline
\end{tabular}


TABLE 8: Sensitivity analysis of free riding $\beta$.

\begin{tabular}{|c|c|c|c|c|c|c|c|c|c|}
\hline$\beta$ & $e^{d *}$ & $e^{c *}$ & $Q_{r}^{d *}$ & $Q_{r}^{c *}$ & $Q_{s}^{d *}$ & $Q_{s}^{c *}$ & $\pi_{r}^{d}$ & $\pi_{s}^{d}$ & $\prod$ \\
\hline 17.5 & 0.35 & 5.91 & 337.76 & 524.88 & 557.83 & 608.47 & 24260.30 & 134134.44 & 181212.17 \\
\hline 15 & 0.70 & 5.93 & 339.84 & 539.72 & 562.29 & 593.88 & 24425.31 & 135807.62 & 181286.16 \\
\hline 12.5 & 1.04 & 5.94 & 343.30 & 554.63 & 565.09 & 579.22 & 24700.72 & 137228.26 & 181360.30 \\
\hline 10 & 1.39 & 5.95 & 348.15 & 569.60 & 566.22 & 564.50 & 25087.16 & 138395.29 & 181434.60 \\
\hline 7.5 & 1.74 & 5.96 & 354.38 & 584.63 & 565.68 & 549.72 & 25585.48 & 139307.22 & 181509.05 \\
\hline 5 & 2.09 & 5.98 & 362.00 & 599.72 & 563.49 & 534.88 & 26196.77 & 139962.15 & 181583.66 \\
\hline 2.5 & 2.43 & 5.99 & 371.00 & 614.88 & 559.63 & 519.97 & 26922.39 & 140357.74 & 181658.42 \\
\hline
\end{tabular}

TABle 9: Coordination analysis.

\begin{tabular}{lccc}
\hline$u$ & $\pi_{r}^{u}$ & $\pi_{s}^{u}$ & $\Pi$ \\
\hline 0.65 & 25982.23 & 155452.37 & 181434.60 \\
0.7 & 27744.06 & 153690.53 & 181434.60 \\
0.75 & 29711.44 & 151723.15 & 181434.60 \\
0.8 & 31922.57 & 149512.03 & 181434.60 \\
0.85 & 34425.73 & 147008.86 & 181434.60 \\
\hline
\end{tabular}

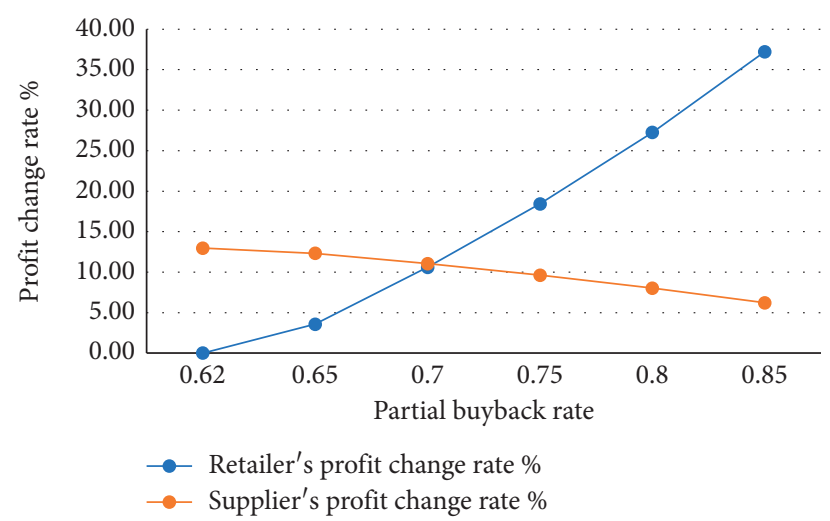

FIgURE 3: Sensitivity of partial buyback contract.

online profits under the decentralized and the centralized decision-makings. Finally, this work proposes a partial buyback contract to coordinate the two channels so as to achieve the win-win status.

Furthermore, this study has the following conclusions and the corresponding managerial implications:

(1) In the dual-channel supply chain involving free riding and consumer switching behavior, the optimal sales effort level, optimal order quantity, and the optimal offline and online profits under the centralized decision-making are more than those under decentralized decision-making, except for the optimal inventory level. Hence, it is fundamental and important to centralize the dual-channel supply chain.

(2) The supplier's wholesale price has negative impact on the optimal sales effort level, the optimal order quantity, and the offline profit in the decentralized system, only has positive impact on the online profit in the decentralized system, and raises the inventory level. Hence, it is vital to keep an appropriate wholesale price so as to stimulate the sales effort level and the offline retailer's order quantity and provide a trade-off between the offline and the online profits.

(3) No matter whether in decentralized or centralized supply chain, the offline sales price is positively related to the optimal sales effort level, the optimal order quantity, the offline and the online profits. It can be seen that, the influence of offline sales price on online profit under the decentralized decisionmaking is different with the result in [35], which is negatively related to the online profit. This shows that, with the higher sales price in offline channel, the risk of bankruptcy of the retailer will reduce, and the impact of price on repayment for the supplier is greater than that on sales loss. Therefore, it implies that the offline retailer is recommended to keep a relatively high sales price if the offline demand is not significantly affected by the price.

(4) The increase of supplier's online sales price will encourage the supplier to keep relatively high inventory level so as to achieve more online profit but has no significant impact on the retailer's offline 
profit, which is same as the result in [35]. And it also has no significant impact on the retailer's sales effort level. Thus, it is reasonable to keep a relatively high online sales price if the online demand is not significantly affected by the price.

(5) The increase of the offline consumer switching rate will lead to the decrease of the offline order quantity and the offline expected profit and raise the online inventory level and the online expected profit, which is consist with the result in [35]. For another, the increase of the online consumer switching rate will raise the offline order quantity and the offline expected profit but has no significant impact on the online inventory level and the online expected profit.

(6) The increase of the free riding coefficient of the supplier, no matter whether in decentralized or centralized systems, will reduce the offline sales effort level, the offline expected profit, and the online expected profit and raise the inventory level. Hence, it is critical to introduce some coordination mechanism to reduce the free riding behavior, so as to achieve the win-win status.
(7) Partial buyback contract can coordinate the dualchannel supply chain members and help them to join the cooperation and achieve the Pareto optimization. The growth rate of each member's profit depends on the partial buyback rate, which is usually determined by their bargaining power and agreements.

In addition, there exist some limitation in this study. (1) This work assumes that demand is mainly affected by free riding behavior and consumer switching behavior and is not significantly affected by the price. (2) It also assumes that both the online supplier and the offline retailer are risk neutral. Hence, the future research will investigate the impact of different risk preferences on the financing decision in dual-channel supply chain taking the price factor into demand function.

\section{Appendix}

Proof. of Proposition 1. In order to determine the optimal value of profit with respect to $Q_{r}^{d}$ and $Q_{s}^{d}$, the following Hessian matrix is obtained:

$$
\begin{aligned}
H= & \left(\begin{array}{cc}
\frac{\partial^{2} \pi_{r}^{d}}{\partial Q_{r}^{2}} & \frac{\partial^{2} \pi_{r}^{d}}{\partial Q_{r} \partial Q_{s}} \\
\frac{\partial^{2} \pi_{s}^{d}}{\partial Q_{s} \partial Q_{r}} & \frac{\partial^{2} \pi_{s}^{d}}{\partial Q_{s}^{2}}
\end{array}\right), \\
\frac{\partial^{2} \pi_{r}^{d}}{\partial Q_{r}^{2}}= & -\left(p_{r}-v\right) \int_{0}^{Q_{s}-\beta e}\left[f\left(Q_{r}-(\alpha-\beta) e\right)\right] g(y) \mathrm{d} y \\
& -\left(p_{r}-v\right) \int_{Q_{s}-\beta e}^{\left(\left(Q_{r}-(\alpha-\beta) e\right) / K_{s}\right)+Q_{s}-\beta e}\left[f\left(Q_{r}-(\alpha-\beta) e-K_{s}\left(y+\beta e-Q_{s}\right)\right)\right] g(y) \mathrm{d} y \\
& +[w(1+I)-v] \int_{0}^{Q_{s}-\beta e}\left[f(z-(\alpha-\beta) e) \frac{w(1+I)-v}{p_{r}-v}\right] g(y) \mathrm{d} y \\
& +[w(1+I)-v] \int_{Q_{s}-\beta e}^{\frac{Q_{r}-(\alpha-\beta) e}{K_{s}}+Q_{s}-\beta e}\left[f\left(z-(\alpha-\beta) e-K_{s}\left(y+\beta e-Q_{s}\right)\right) \frac{w(1+I)-v}{p_{r}-v}\right] g(y) \mathrm{d} y,
\end{aligned}
$$




$$
\begin{aligned}
\frac{\partial^{2} \pi_{r}^{d}}{\partial Q_{r} \partial Q_{s}} & =-\left(p_{r}-v\right) K_{s} \int_{Q_{s}-\beta e}^{\left(\left(Q_{r}-(\alpha-\beta) e\right) / K_{s}\right)+Q_{s}-\beta e}\left[f\left(Q_{r}-(\alpha-\beta) e-K_{s}\left(y+\beta e-Q_{s}\right)\right)\right] g(y) \mathrm{d} y \\
& +[w(1+I)-v] K_{s} \int_{Q_{s}-\beta e}^{\left(\left(Q_{r}-(\alpha-\beta) e\right) / K_{s}\right)+Q_{s}-\beta e}\left[f\left(z-(\alpha-\beta) e-K_{s}\left(y+\beta e-Q_{s}\right)\right)\right] g(y) \mathrm{d} y, \\
\frac{\partial^{2} \pi_{s}^{d}}{\partial Q_{s}^{2}}= & -\left(p_{s}-v\right)\left[\int_{0}^{Q_{r}-(\alpha-\beta) e} g\left(Q_{s}-\beta e\right) f(x) \mathrm{d} x+\int_{Q_{r}-(\alpha-\beta) e}^{\left(\left(Q_{s}-\beta e\right) / K_{r}\right)+Q_{r}-(\alpha-\beta) e} g\left(Q_{s}-\beta e-K_{r}\left(x+(\alpha-\beta) e-Q_{r}\right)\right) f(x) \mathrm{d} x\right] \\
& +\left(p_{r}-v\right) K_{s} \int_{0}^{z-(\alpha-\beta) e} g\left(Q_{s}-\beta e\right) f(x) \mathrm{d} x \\
& -\left(p_{r}-v\right) K_{s}^{2} \int_{Q_{s}-\beta e}^{\left(\left(Q_{r}-(\alpha-\beta) e\right) / K_{s}\right)+Q_{s}-\beta e} f\left(z-(\alpha-\beta) e-K_{s}\left(y+\beta e-Q_{s}\right)\right) g(y) \mathrm{d} y, \\
\frac{\partial^{2} \pi_{s}^{d}}{\partial Q_{s} \partial Q_{r}} & -K_{r}\left(p_{s}-v\right) \int_{Q_{r}-(\alpha-\beta) e}^{\left(\left(Q_{s}-\beta e\right) / K_{r}\right)+Q_{r}-(\alpha-\beta) e} g\left(Q_{s}-\beta e-K_{r}\left(x+(\alpha-\beta) e-Q_{r}\right)\right) f(x) \mathrm{d} x \\
-[w(1 & +I)-v] K_{s} \int_{Q_{s}-\beta e}^{\left(\left(Q_{r}-(\alpha-\beta) e\right) / K_{s}\right)+Q_{s}-\beta e} f\left(z-(\alpha-\beta) e-K_{s}\left(y+\beta e-Q_{s}\right)\right) g(y) \mathrm{d} y .
\end{aligned}
$$

It is obvious that $\left(\partial^{2} \pi_{r}^{d} / \quad \partial Q_{r}^{2}\right)<0,\left(\partial^{2} \pi_{s}^{d} /\right.$ $\left.\partial Q_{s}^{2}\right)<0,\left(\partial^{2} \pi_{r}^{d} / \partial Q_{r} \partial Q_{s}\right)<0,\left(\partial^{2} \pi_{s}^{d} / \partial Q_{s} \partial Q_{r}\right)<0$.

In addition,

$$
J=\left|\begin{array}{cc}
\frac{\partial^{2} \pi_{r}^{d}}{\partial Q_{r}^{2}} & \frac{\partial^{2} \pi_{r}^{d}}{\partial Q_{r} \partial Q_{s}} \\
\frac{\partial^{2} \pi_{s}^{d}}{\partial Q_{s} \partial Q_{r}} & \frac{\partial^{2} \pi_{s}^{d}}{\partial Q_{s}^{2}}
\end{array}\right|=\frac{\partial^{2} \pi_{r}^{d}}{\partial Q_{r}^{2}} \frac{\partial^{2} \pi_{s}^{d}}{\partial Q_{s}^{2}}-\frac{\partial^{2} \pi_{r}^{d}}{\partial Q_{r} \partial Q_{s}} \frac{\partial^{2} \pi_{s}^{d}}{\partial Q_{s} \partial Q_{r}}
$$

It is found that, if $\left(p_{r}-v\right) K_{s}>w(1+I)-v$, then $\left|\partial^{2} \pi_{r}^{d} / \partial Q_{r}^{2}\right|>\left|\partial^{2} \pi_{r}^{d} / \partial Q_{r} \partial Q_{s}\right|,\left|\partial^{2} \pi_{s}^{d} / \partial Q_{s}^{2}\right|>\left|\partial^{2} \pi_{s}^{d} / \partial Q_{s} \partial Q_{r}\right|$, and $|J|=\left(\partial^{2} \pi_{r}^{d} / \partial Q_{r}^{2}\right)\left(\partial^{2} \pi_{s}^{d} / \partial Q_{s}^{2}\right)-\left(\partial^{2} \pi_{r}^{d} / \partial Q_{r} \partial Q_{s}\right)\left(\partial^{2} \pi_{s}^{d} / \partial Q_{s}\right.$ $\left.\partial Q_{r}\right)>0$. Thus, for any given sales effort level $e^{d}$, if $\left(p_{r}-v\right) K_{s}>w(1+I)-v$, the supplier's total expected profit $\pi_{s}^{d}$ and the retailer's total expected profit $\pi_{r}^{d}$ are strictly jointly concave in $Q_{s}^{d}$ and $Q_{r}^{d}$. Otherwise, $\pi_{s}^{d}$ and $\pi_{r}^{d}$ are jointly concave in $Q_{s}^{d}$ and $Q_{r}^{d}$ if $|J|=\left(\partial^{2} \pi_{r}^{d /}\right.$ $\left.\partial Q_{r}^{2}\right)\left(\partial^{2} \pi_{s}^{d} / \partial Q_{s}^{2}\right)-\left(\partial^{2} \pi_{r}^{d} / \partial Q_{r} \partial Q_{s}\right)\left(\partial^{2} \pi_{s}^{d} / \partial Q_{s} \partial Q_{r}\right)>0$

Proof. of Proposition 2. The optimal sales effort level $e^{d *}$ can be obtained by calculating the first derivative of the retailer's expected profit with respect to the sales effort level and making it equal to zero and combining with the implicit function theorem.

Among them,

$$
\begin{aligned}
& \frac{\mathrm{d} Q_{r}(e)}{\mathrm{d} e}=-\frac{1}{J}\left|\begin{array}{ll}
\frac{\partial F_{r}^{d}}{\partial e} & \frac{\partial F_{r}^{d}}{\partial Q_{s}} \\
\frac{\partial F_{s}^{d}}{\partial e} & \frac{\partial F_{s}^{d}}{\partial Q_{s}}
\end{array}\right|=-\frac{1}{J}\left(\frac{\partial^{2} \pi_{r}^{d}}{\partial Q_{r} \partial e} \frac{\partial^{2} \pi_{s}^{d}}{\partial Q_{s}^{2}}-\frac{\partial^{2} \pi_{r}^{d}}{\partial Q_{r} \partial Q_{s}} \frac{\partial^{2} \pi_{s}^{d}}{\partial Q_{s} \partial e}\right), \\
& \frac{\mathrm{dQ}_{s}(e)}{\mathrm{d} e}=-\frac{1}{J}\left|\begin{array}{ll}
\frac{\partial F_{r}^{d}}{\partial Q_{r}} & \frac{\partial F_{r}^{d}}{\partial e} \\
\frac{\partial F_{s}^{d}}{\partial Q_{r}} & \frac{\partial F_{s}^{d}}{\partial e}
\end{array}\right|=-\frac{1}{J}\left(\frac{\partial^{2} \pi_{r}^{d}}{\partial Q_{r}^{2}} \frac{\partial^{2} \pi_{s}^{d}}{\partial Q_{s} \partial e}-\frac{\partial^{2} \pi_{r}^{d}}{\partial Q_{r} \partial e} \frac{\partial^{2} \pi_{s}^{d}}{\partial Q_{s} \partial Q_{r}}\right),
\end{aligned}
$$




$$
\begin{aligned}
& \frac{\partial^{2} \pi_{r}^{d}}{\partial Q_{r} \partial e}=\left(p_{r}-v\right)\left[(\alpha-\beta)+K_{s} \beta\right] \int_{Q_{s}-\beta e}^{\left(\left(Q_{r}-(\alpha-\beta) e\right) / K_{s}\right)+Q_{s}-\beta e}\left[f\left(Q_{r}-(\alpha-\beta) e-K_{s}\left(y+\beta e-Q_{s}\right)\right)\right] g(y) \mathrm{d} y \\
& +\left(p_{r}-v\right)(\alpha-\beta) \int_{0}^{Q_{s}-\beta e}\left[f\left(Q_{r}-(\alpha-\beta) e\right)\right] g(y) \mathrm{d} y \\
& +[w(1+I)-v]\left[\frac{\eta e(1+I)}{p_{r}-v}-(\alpha-\beta)\right] \int_{0}^{Q_{s}-\beta e}[f(z-(\alpha-\beta) e)] g(y) \mathrm{d} y \\
& +[w(1+I)-v]\left[\frac{\eta e(1+I)}{p_{r}-v}-(\alpha-\beta)-K_{s} \beta\right] \int_{Q_{s}-\beta e}^{\left(\left(Q_{r}-(\alpha-\beta) e\right) / K_{s}\right)+Q_{s}-\beta e}\left[f\left(z-(\alpha-\beta) e-K_{s}\left(y+\beta e-Q_{s}\right)\right)\right] g(y) \mathrm{d} y, \\
& \frac{\partial^{2} \pi_{s}^{d}}{\partial Q_{s} \partial e}=\left(p_{s}-v\right)\left[\beta \int_{0}^{Q_{r}-(\alpha-\beta) e} g\left(Q_{s}-\beta e\right) f(x) \mathrm{d} x+\left(\beta+K_{r}(\alpha-\beta)\right)\right. \\
& \left.\cdot \int_{Q_{r}-(\alpha-\beta) e}^{\left(\left(Q_{s}-\beta e\right) / K_{r}\right)+Q_{r}-(\alpha-\beta) e} g\left(Q_{s}-\beta e-K_{r}\left(x+(\alpha-\beta) e-Q_{r}\right)\right) f(x) \mathrm{d} x\right] \\
& -\beta\left(p_{r}-v\right) K_{s} \int_{0}^{z-(\alpha-\beta) e} g\left(Q_{s}-\beta e\right) f(x) \mathrm{d} x \\
& -\left(p_{r}-v\right) K_{s}\left[\frac{\eta e(1+I)}{p_{r}-v}-(\alpha-\beta)-K_{s} \beta\right] \int_{Q_{s}-\beta e}^{\left(\left(Q_{r}-(\alpha-\beta) e\right) / K_{s}\right)+Q_{s}-\beta e} f\left(z-(\alpha-\beta) e-K_{s}\left(y+\beta e-Q_{s}\right)\right) g(y) \mathrm{d} y \\
& \frac{\partial \pi_{r}^{d}}{\partial Q_{s}}=-\left(p_{r}-v\right) K_{s} \int_{Q_{s}-\beta e}^{\left(\left(Q_{r}-(\alpha-\beta) e\right) / K_{s}\right)+Q_{s}-\beta e} \int_{z-(\alpha-\beta) e-K_{s}\left(y+\beta e-Q_{s}\right)}^{Q_{r}-(\alpha-\beta) e-K_{s}\left(y+\beta e-Q_{s}\right)} f(x) g(y) \mathrm{d} x \mathrm{~d} y, \\
& \frac{\partial \pi_{r}^{d}}{\partial e}=-\eta e(1+I)+\left(p_{r}-v\right)\left(\alpha-\beta+K_{s} \beta\right) \int_{Q_{s}-\beta e}^{\left(\left(Q_{r}-(\alpha-\beta) e\right) / K_{s}\right)+Q_{s}-\beta e} \int_{z-(\alpha-\beta) e-K_{s}\left(y+\beta e-Q_{s}\right)}^{Q_{r}-(\alpha-\beta) e-K_{s}\left(y+\beta e-Q_{s}\right)} f(x) g(y) \mathrm{d} x \mathrm{~d} y \\
& +\left(p_{r}-v\right)(\alpha-\beta) \int_{0}^{Q_{s}-\beta e} \int_{z-(\alpha-\beta) e}^{Q_{r}-(\alpha-\beta) e} f(x) g(y) \mathrm{d} x \mathrm{~d} y \\
& +\eta e(1+I) \int_{0}^{Q_{s}-\beta e} \int_{0}^{z-(\alpha-\beta) e} f(x) g(y) \mathrm{d} x \mathrm{~d} y \\
& +\eta e(1+I) \int_{Q_{s}-\beta e}^{\left(\left(Q_{r}-(\alpha-\beta) e\right) / K_{s}\right)+Q_{s}-\beta e} \int_{0}^{z-(\alpha-\beta) e-K_{s}\left(y+\beta e-Q_{s}\right)} f(x) g(y) \mathrm{d} x \mathrm{~d} y .
\end{aligned}
$$

Proof. of Proposition 3.

In order to determine the optimal value of the overall profit of the supply chain with respect to $Q_{r}$ and $Q_{s}$, the following Hessian matrix is obtained:

$$
\widehat{H}=\left(\begin{array}{cc}
\frac{\partial^{2} \Pi}{\partial Q_{r}^{2}} & \frac{\partial^{2} \Pi}{\partial Q_{r} \partial Q_{s}} \\
\frac{\partial^{2} \Pi}{\partial Q_{s} \partial Q_{r}} & \frac{\partial^{2} \Pi}{\partial Q_{s}^{2}}
\end{array}\right) .
$$


Furthermore,

$$
\begin{aligned}
& \frac{\partial^{2} \Pi}{\partial Q_{r}^{2}}=-\left[p_{r}-v-K_{r}\left(p_{s}-v\right)\right] \int_{0}^{Q_{s}-\beta e}\left[f\left(Q_{r}-(\alpha-\beta) e\right)\right] g(y) \mathrm{d} y \\
& -\left(p_{r}-v\right) \int_{Q_{s}-\beta e}^{\left(\left(Q_{r}-(\alpha-\beta) e\right) / K_{s}\right)+Q_{s}-\beta e}\left[f\left(Q_{r}-(\alpha-\beta) e-K_{s}\left(y+\beta e-Q_{s}\right)\right)\right] g(y) \mathrm{d} y \\
& -K_{r}^{2}\left(p_{s}-v\right) \int_{Q_{r}-(\alpha-\beta) e}^{\left(\left(Q_{s}-\beta e\right) / K_{r}\right)+Q_{r}-(\alpha-\beta) e} g\left(Q_{s}-\beta e-K_{r}\left(x+(\alpha-\beta) e-Q_{r}\right)\right) f(x) \mathrm{d} x, \\
& \frac{\partial^{2} \Pi}{\partial Q_{s}^{2}}=-\left[p_{s}-v-K_{s}\left(p_{r}-v\right)\right] \int_{0}^{Q_{r}-(\alpha-\beta) e} g\left(Q_{s}-\beta e\right) f(x) \mathrm{d} x \\
& -\left(p_{s}-v\right) \int_{Q_{r}-(\alpha-\beta) e}^{\left(\left(Q_{s}-\beta e\right) / K_{r}\right)+Q_{r}-(\alpha-\beta) e} g\left(Q_{s}-\beta e-K_{r}\left(x+(\alpha-\beta) e-Q_{r}\right)\right) f(x) \mathrm{d} x \\
& -\left(p_{s}-v\right) K_{s}^{2} \int_{Q_{s}-\beta e}^{\left(\left(Q_{r}-(\alpha-\beta) e\right) / K_{s}\right)+Q_{s}-\beta e} f\left(Q_{r}-(\alpha-\beta) e-K_{s}\left(y+\beta e-Q_{s}\right)\right) g(y) \mathrm{d} y, \\
& \frac{\partial^{2} \prod}{\partial Q_{r} \partial Q_{s}}=\frac{\partial^{2} \prod}{\partial Q_{s} \partial Q_{r}}=-K_{r}\left(p_{s}-v\right) \int_{Q_{r}-(\alpha-\beta) e}^{\left(\left(Q_{s}-\beta e\right) / K_{r}\right)+Q_{r}-(\alpha-\beta) e} g\left(Q_{s}-\beta e-K_{r}\left(x+(\alpha-\beta) e-Q_{r}\right)\right) f(x) \mathrm{d} x \\
& -K_{s}\left(p_{r}-v\right) \int_{Q_{s}-\beta e}^{\left(\left(Q_{r}-(\alpha-\beta) e\right) / K_{s}\right)+Q_{s}-\beta e} f\left(Q_{r}-(\alpha-\beta) e-K_{s}\left(y+\beta e-Q_{s}\right)\right) g(y) \mathrm{d} y .
\end{aligned}
$$

In addition,

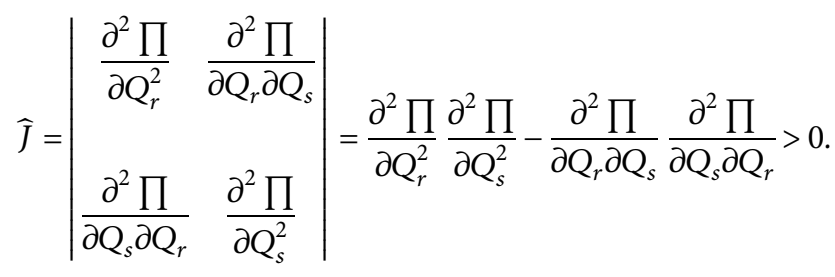

Because $\left(p_{r}-v\right)>K_{r}\left(p_{s}-v\right)$ and $\left(p_{s}-v\right)>K_{s}\left(p_{r}-v\right)$, it is easy to prove that $\left(\partial^{2} \prod / \partial Q_{r}^{2}\right)<0,\left(\partial^{2} \prod /\right.$ $\left.\partial Q_{s}^{2}\right)<0,\left(\partial^{2} \prod / \partial Q_{r} \partial Q_{s}\right)<0,\left(\partial^{2} \prod / \partial Q_{s} \partial Q_{r}\right)<0$, and $|\widehat{J}|=$ $\left(\partial^{2} \prod / \partial Q_{r}^{2}\right)\left(\partial^{2} \prod / \partial Q_{s}^{2}\right)-\left(\partial^{2} \prod / \partial Q_{r} \partial Q_{s}\right)\left(\partial^{2} \prod / \partial Q_{s}\right.$

$\left.\partial Q_{r}\right)>0$. Therefore, under the centralized scenario, the overall expected profit of centralized dual-channel supply chain $\Pi$ is strictly jointly concave in $Q_{r}^{c}$ and $Q_{s}^{c}$.

However, there is no more evidence to make sure that

$$
\widetilde{J}=\left|\begin{array}{cc}
\frac{\partial^{2} \prod}{\partial Q_{s}^{2}} & \frac{\partial^{2} \Pi}{\partial Q_{s} \partial e} \\
\frac{\partial^{2} \prod}{\partial e \partial Q_{s}} & \frac{\partial^{2} \Pi}{\partial e^{2}}
\end{array}\right|>0
$$

Thus, $\prod$ is indefinite with respect to $Q_{s}^{c}$ and $e^{c}$. Therefore, $\Pi$ is not jointly concave in $Q_{r}^{c}, Q_{s}^{c}$, and $e^{c}$.

Proof of Proposition 4. The optimal sales effort level $e^{c *}$ can be obtained by calculating the first derivative of the retailer's expected profit with respect to the sales effort level and making it equal to zero and combining with the implicit function theorem.

Proof of Lemma 1 


$$
\begin{aligned}
& \frac{\partial^{2} \Pi}{\partial Q_{r} \partial e}=(\alpha-\beta)\left(p_{r}-v\right) \int_{0}^{Q_{s}-\beta e}\left[f\left(Q_{r}-(\alpha-\beta) e\right)\right] g(y) \mathrm{d} y \\
& +\left(\alpha-\beta+K_{s} \beta\right)\left(p_{r}-v\right) \int_{Q_{s}-\beta e}^{\left(\left(Q_{r}-(\alpha-\beta) e\right) / K_{s}\right)+Q_{s}-\beta e}\left[f\left(Q_{r}-(\alpha-\beta) e-K_{s}\left(y+\beta e-Q_{s}\right)\right)\right] g(y) \mathrm{d} y \\
& -(\alpha-\beta) K_{r}\left(p_{s}-v\right) \int_{0}^{Q_{s}-\beta e} f\left(Q_{r}-(\alpha-\beta) e\right) g(y) \mathrm{d} y \\
& +\left[\beta+K_{r}(\alpha-\beta)\right] K_{r}\left(p_{s}-v\right) \int_{Q_{r}-(\alpha-\beta) e}^{\left(\left(Q_{s}-\beta e\right) / K_{r}\right)+Q_{r}-(\alpha-\beta) e} g\left(Q_{s}-\beta e-K_{r}\left(x+(\alpha-\beta) e-Q_{r}\right)\right) f(x) \mathrm{d} x, \\
& \frac{\partial^{2} \Pi}{\partial Q_{s} \partial e}=\beta\left(p_{s}-v\right) \int_{0}^{Q_{r}-(\alpha-\beta) e} g\left(Q_{s}-\beta e\right) f(x) \mathrm{d} x \\
& +\left[\beta+K_{r}(\alpha-\beta)\right]\left(p_{s}-v\right) \int_{Q_{r}-(\alpha-\beta) e}^{\left(\left(Q_{s}-\beta e\right) / K_{r}\right)+Q_{r}-(\alpha-\beta) e} g\left(Q_{s}-\beta e-K_{r}\left(x+(\alpha-\beta) e-Q_{r}\right)\right) f(x) \mathrm{d} x \\
& -\beta K_{s}\left(p_{r}-v\right) \int_{0}^{Q_{r}-(\alpha-\beta) e} g\left(Q_{s}-\beta e\right) f(x) \mathrm{d} x \\
& +\left[(\alpha-\beta)+K_{s} \beta\right] K_{s}\left(p_{r}-v\right) \int_{Q_{s}-\beta e}^{\left(\left(Q_{r}-(\alpha-\beta) e\right) / K_{s}\right)+Q_{s}-\beta e} f\left(Q_{r}-(\alpha-\beta) e-K_{s}\left(y+\beta e-Q_{s}\right)\right) g(y) \mathrm{d} y, \\
& \frac{\partial \prod}{\partial e}=-\eta e+(\alpha-\beta)\left(p_{r}-v\right) \int_{0}^{Q_{s}-\beta e} \int_{0}^{Q_{r}-(\alpha-\beta) e} f(x) g(y) \mathrm{d} x \mathrm{~d} y \\
& +\beta\left(p_{s}-v\right) \int_{0}^{Q_{s}-\beta e} \int_{0}^{Q_{r}-(\alpha-\beta) e} f(x) g(y) \mathrm{d} x \mathrm{~d} y \\
& +\left(p_{r}-v\right)\left[(\alpha-\beta)+K_{s} \beta\right] \int_{Q_{s}-\beta e}^{\left(\left(Q_{r}-(\alpha-\beta) e\right) / K_{s}\right)+Q_{s}-\beta e} \int_{0}^{Q_{r}-(\alpha-\beta) e-K_{s}\left(y+\beta e-Q_{s}\right)} f(x) g(y) \mathrm{d} x \mathrm{~d} y \\
& +\left(p_{s}-v\right)\left[\beta+K_{r}(\alpha-\beta)\right] \int_{Q_{r}-(\alpha-\beta) e}^{\left(\left(Q_{s}-\beta e\right) / K_{r}\right)+Q_{r}-(\alpha-\beta) e} \int_{0}^{Q_{s}-\beta e-K_{r}\left(x+(\alpha-\beta) e-Q_{r}\right)} g(y) f(x) \mathrm{d} y \mathrm{~d} x .
\end{aligned}
$$

Hence,

$$
\begin{aligned}
& \frac{\mathrm{d} Q_{r}(e)}{\mathrm{d} e}=-\frac{1}{\widehat{J}}\left(\frac{\partial^{2} \Pi}{\partial Q_{r} \partial e} \frac{\partial^{2} \Pi}{\partial Q_{s}^{2}}-\frac{\partial^{2} \Pi}{\partial Q_{r} \partial Q_{s}} \frac{\partial^{2} \Pi}{\partial Q_{s} \partial e}\right)=(\alpha-\beta)>0, \\
& \frac{\mathrm{d} Q_{s}(e)}{\mathrm{d} e}=-\frac{1}{\widehat{J}}\left(\frac{\partial^{2} \Pi}{\partial Q_{r}^{2}} \frac{\partial^{2} \Pi}{\partial Q_{s} \partial e}-\frac{\partial^{2} \Pi}{\partial Q_{r} \partial e} \frac{\partial^{2} \Pi}{\partial Q_{s} \partial Q_{r}}\right)=\beta>0 .
\end{aligned}
$$

Proof. of Lemma 2.

When the demand is uniformly distributed, $d_{r} \sim U(0, \theta), d_{s} \sim U(0, \theta)$, it can be obtained as follows:

$$
\begin{aligned}
\frac{\partial \prod}{\partial Q_{r}} \frac{\mathrm{d} Q_{r}(e)}{\mathrm{d} e}+\frac{\partial \prod}{\partial Q_{s}} \frac{\mathrm{d} Q_{s}(e)}{\mathrm{d} e}+\frac{\partial \prod}{\partial e}= & \left(p_{r}-c_{o}\right)(\alpha-\beta)-\eta e \\
& +\beta\left(p_{s}-c\right) .
\end{aligned}
$$

And it is obvious that $\left(\mathrm{d}^{2} \prod / \mathrm{d}^{2} e\right)=-\eta<0$, which means that the expected profit $\prod$ of the whole supply chain is a strict concave function of the retailer's sales effort level $e^{c}$.

\section{Data Availability}

The data used to support the findings of this study are included within the article.

\section{Conflicts of Interest}

The authors declare that they have no conflicts of interest.

\section{Acknowledgments}

This study was supported by the Department of Science and Technology of Guangdong Province (grant no. 2020A0505090004).

\section{References}

[1] N. Yan, X. Jin, H. Zhong, and X. Xu, "Loss-averse retailers' financial offerings to capital-constrained suppliers: loan vs. 
investment," International Journal of Production Economics, vol. 227, 2020.

[2] J. Huang, W. Yang, and Y. Tu, "Financing mode decision in a supply chain with financial constraint," International Journal of Production Economics, vol. 220, 2020.

[3] B. Jing, X. Chen, and G. G. Cai, "Equilibrium financing in a distribution channel with capital constraint," Production and Operations Management, vol. 21, no. 6, pp. 1090-1101, 2012.

[4] S. Hua, J. Liu, T. C. E. Cheng, and X. Zhai, "Financing and ordering strategies for a supply chain under the option contract," International Journal of Production Economics, vol. 208, pp. 100-121, 2019.

[5] W.-y. K. Chiang, D. Chhajed, and J. D. Hess, "Direct marketing, indirect profits: a strategic analysis of dual-channel supply-chain design," Management Science, vol. 49, no. 1, pp. 1-20, 2003.

[6] G. Hua, S. Wang, and T. C. E. Cheng, "Price and lead time decisions in dual-channel supply chains," European Journal of Operational Research, vol. 205, no. 1, pp. 113-126, 2010.

[7] ChinaSSPP. Explore how Sephora makes customers inseparable by connecting online and offline. 2018; http://www. chinasspp.com/News/Detail/2018-2-28/405714.htm.

[8] J. Qin, L. Ren, L. Xia, Z. Wang, and H. Chang, "Pricing strategies for dual-channel supply chains under a trade credit policy," International Transactions in Operational Research, vol. 27, no. 5, pp. 2469-2508, 2020.

[9] G. Cai, "Channel selection and coordination in dual-channel supply chains," Journal of Retailing, vol. 86, no. 1, pp. 22-36, 2010.

[10] G. Xu, B. Dan, X. Zhang, and C. Liu, "Coordinating a dualchannel supply chain with risk-averse under a two-way revenue sharing contract," International Journal of Production Economics, vol. 147, pp. 171-179, 2014.

[11] G. J. Fitzsimons, "Consumer response to stockouts," Journal of Consumer Research, vol. 27, no. 2, pp. 249-266, 2000.

[12] Y.-W. Zhou, J. Guo, and W. Zhou, "Pricing/service strategies for a dual-channel supply chain with free riding and servicecost sharing," International Journal of Production Economics, vol. 196, pp. 198-210, 2018.

[13] D. Xing and T. Liu, "Sales effort free riding and coordination with price match and channel rebate," European Journal of Operational Research, vol. 219, no. 2, pp. 264-271, 2012.

[14] J. Heydari and J. Asl-Najafi, "A revised sales rebate contract with effort-dependent demand: a channel coordination approach," International Transactions in Operational Research, vol. 28, no. 1, pp. 438-469, 2018.

[15] L. M. Gelsomino, R. Mangiaracina, A. Perego, and A. Tumino, "Supply chain finance: a literature review," International Journal of Physical Distribution \& Logistics Management, vol. 46, no. 4, pp. 348-366, 2016.

[16] D. A. Wuttke, C. Blome, H. Sebastian Heese, and M. Protopappa-Sieke, "Supply chain finance: optimal introduction and adoption decisions," International Journal of Production Economics, vol. 178, pp. 72-81, 2016.

[17] M. J. Brennan, V. Maksimovics, and J. Zechner, "Vendor financing," The Journal of Finance, vol. 43, no. 5, pp. 1127-1141, 1988.

[18] M. Dada and Q. Hu, "Financing newsvendor inventory," Operations Research Letters, vol. 36, no. 5, pp. 569-573, 2008.

[19] X. Chen and G. Cai, "Joint logistics and financial services by a 3PL firm," European Journal of Operational Research, vol. 214, no. 3, pp. 579-587, 2011.

[20] Y. Feng, Y. Mu, B. Hu, and A. Kumar, "Commodity options purchasing and credit financing under capital constraint,"
International Journal of Production Economics, vol. 153, pp. 230-237, 2014.

[21] N. Yan, B. Sun, H. Zhang, and C. Liu, "A partial credit guarantee contract in a capital-constrained supply chain: financing equilibrium and coordinating strategy," International Journal of Production Economics, vol. 173, pp. 122-133, 2016.

[22] P. Kouvelis and W. Zhao, "Financing the newsvendor: supplier vs. Bank, and the structure of optimal trade credit contracts," Operations Research, vol. 60, no. 3, pp. 566-580, 2012.

[23] B. Jing and A. Seidmann, "Finance sourcing in a supply chain," Decision Support Systems, vol. 58, pp. 15-20, 2014.

[24] C. S. Tang, S. A. Yang, and J. Wu, "Sourcing from suppliers with financial constraints and performance risk," Manufacturing \& Service Operations Management, vol. 20, no. 1, pp. 70-84, 2018.

[25] S. A. Yang and J. R. Birge, "Trade credit, risk sharing, and inventory financing portfolios," Management Science, vol. 64, no. 8, pp. 3667-3689, 2018.

[26] J. Chen, H. Zhang, and Y. Sun, "Implementing coordination contracts in a manufacturer Stackelberg dual-channel supply chain," Omega, vol. 40, no. 5, pp. 571-583, 2012.

[27] W.-m. Ma, Z. Zhao, and H. Ke, "Dual-channel closed-loop supply chain with government consumption-subsidy," European Journal of Operational Research, vol. 226, no. 2, pp. 221-227, 2013.

[28] Q. Ding, C. Dong, and Z. Pan, "A hierarchical pricing decision process on a dual-channel problem with one manufacturer and one retailer," International Journal of Production Economics, vol. 175, pp. 197-212, 2016.

[29] L. F. Dai, X. Wang, X. Liu, and L. Wei, "Pricing strategies in dual-channel supply chain with a fair caring retailer," Complexity, vol. 2019, 23 pages, 2019.

[30] L. M. Wang, Q. K. Song, and Z. J. Zhao, "The optimal pricing of dual-channel supply chain with the third party product recovery and sales effort," Complexity, vol. 2020, Article ID 4951341, 18 pages, 2020.

[31] L. Xu, J. Shi, and J. H. Chen, "Effect of capital constraint in a dual-channel supply chain," Complexity, vol. 2020, Article ID 1585270, 14 pages, 2020.

[32] W.-y. Kevin Chiang and G. E. Monahan, "Managing inventories in a two-echelon dual-channel supply chain," European Journal of Operational Research, vol. 162, no. 2, pp. 325-341, 2005.

[33] T. Boyaci, "Competitive stocking and coordination in a multiple-channel distribution system," IIE Transactions, vol. 37, no. 5, pp. 407-427, 2005.

[34] Q. Geng and S. Mallik, "Inventory competition and allocation in a multi-channel distribution system," European Journal of Operational Research, vol. 182, no. 2, pp. 704-729, 2007.

[35] J. Q. Yang, X. M. Zhang, H. Y. Fu, and C. Liu, "Inventory competition in a dual-channel supply chain with delivery lead time consideration," Applied Mathematical Modelling, vol. 42, pp. 675-692, 2017.

[36] S. van Baal and C. Dach, "Free riding and customer retention across retailers' channels," Journal of Interactive Marketing, vol. 19, no. 2, pp. 75-85, 2005.

[37] R. He, Y. Xiong, and Z. Lin, "Carbon emissions in a dual channel closed loop supply chain: the impact of consumer free riding behavior," Journal of Cleaner Production, vol. 134, pp. 384-394, 2016.

[38] J. Chen and B. Chen, "When should the offline retailer implement price matching?" European Journal of Operational Research, vol. 277, no. 3, pp. 996-1009, 2019. 
[39] F. Zhang, Z. Zhang, Y. Xue, J. Zhang, and Y. Che, "Dynamic green innovation decision of the supply chain with innovating and free-riding manufacturers: cooperation and spillover," Complexity, vol. 2020, Article ID 8937847, 17 pages, 2020.

[40] N. Yan, Y. Zhang, X. Xu, and Y. Gao, "Online finance with dual channels and bidirectional free-riding effect," International Journal of Production Economics, vol. 231, 2020.

[41] J. Li and L. Liu, "Supply chain coordination with quantity discount policy," International Journal of Production Economics, vol. 101, no. 1, pp. 89-98, 2006.

[42] G. P. Cachon and M. A. Lariviere, "Supply chain coordination with revenue-sharing contracts: strengths and limitations," Management Science, vol. 51, no. 1, pp. 30-44, 2005.

[43] B. A. Pasternack, "Optimal pricing and return policies for perishable commodities," Marketing Science, vol. 4, no. 2, pp. 166-176, 1985.

[44] A. A. Tsay, "The quantity flexibility contract and suppliercustomer incentives," Management Science, vol. 45, no. 10, pp. 1339-1358, 1999.

[45] S. Jorgensen, S. P. Sigue, and G. Zaccour, "Dynamic cooperative advertising in a channel," Journal of Retailing, vol. 76, no. 1, pp. 71-92, 2000.

[46] Y. Xie, X. Liang, L. Ma, and H. Yan, "Empty container management and coordination in intermodal transport," European Journal of Operational Research, vol. 257, no. 1, pp. 223-232, 2017.

[47] Y. G. Zhong, F. Guo, Z. Wang, and H. Tang, "Coordination analysis of revenue sharing in E-commerce logistics service supply chain with cooperative distribution," Sage Open, vol. 9, no. 3, 2019.

[48] L. Xie, J. Ma, and M. Goh, "Supply chain coordination in the presence of uncertain yield and demand," International Journal of Production Research, vol. 263, pp. 1-17, 2020.

[49] Y. Zhong, F. Guo, H. Tang, and X. Chen, "Research on coordination complexity of E-commerce logistics service supply chain," Complexity, vol. 2020, Article ID 7031543, 21 pages, 2020.

[50] E. Ofek, Z. Katona, and M. Sarvary, “"Bricks and clicks”: the impact of product returns on the strategies of multichannel retailers," Marketing Science, vol. 30, no. 1, pp. 42-60, 2011.

[51] D. A. Phan, T. L. H. Vo, and A. N. Lai, "Supply chain coordination under trade credit and retailer effort," International Journal of Production Research, vol. 57, no. 9, pp. 2642-2655, 2019. 